ARTÍCULO

\title{
UNA SENDA DE PLATA Y SANGRE \\ EL CAMINO MILITAR DE LA VÍA POR XALAPA DEL CAMINO REAL DE VERACRUZ, 1811-1816
}

\section{A PATH OF SILVER AND BLOOD \\ THE MILITARY TRAIL OF THE ROUTE THROUGH XALAPA OF THE ROYAL ROAD OF VERACRUZ, 1811-1816}

\author{
Sergio A. VArgas Matías \\ Universidad Michoacana de San Nicolás de Hidalgo \\ Instituto de Investigaciones Históricas \\ s.arturo.vargas.m@outlook.com
}

\section{Resumen}

El presente artículo da cuenta del establecimiento del “camino militar" en la ruta por Xalapa del Camino Real de Veracruz durante la guerra de Independencia mexicana. Con base en documentación inédita hallada en diversos archivos de México y España, el texto expone los diferentes proyectos bosquejados entre 1811 y 1816 por el gobierno virreinal para recuperar el control del itinerario, enfocándose además en las novedades técnicas puestas en operación por el brigadier realista Fernando Miyares y Mancebo en la edificación de los bastiones que conformaron la estructura de defensa instrumentada por este personaje en el trayecto Xalapa-Veracruz.

Palabras clave: Camino Real, guerra de Independencia, Veracruz, fortificaciones.

\begin{abstract}
This article reports on the establishment of the "military road" on the route through Xalapa del Camino Real de Veracruz during the Mexican War of Independence. Based on unpublished documentation found in various archives in Mexico and Spain, the text presents the different projects sketched between 1811 and 1816 by the viceroyal government to regain control of the itinerary, also focusing on the new techniques put into operation by the realistic brigadier Fernando Miyares y Mancebo in the construction of the bastions that formed the defense structure implemented by this character in the Xalapa-Veracruz route.
\end{abstract}

Keywords: Royal Road, War of Independence, Veracruz, fortifications.

\section{Información del artículo}

Recibido: 23 de julio de 2018.

Aceptado: 14 de noviembre de 2018.

DOI: $10.22201 /$ iih.24486922e.2019.60.65600 


\section{La RUta POR Xalapa del Camino Real de VeracruZ}

Durante el periodo colonial, el Camino Real ${ }^{1}$ de Veracruz fue la vía de comunicación más importante de la Nueva España, debido a la estratégica posición de la plaza veracruzana en las costas del golfo de México - a corta distancia de Cuba, lo que le confería un significativo papel como parte de la estructura defensiva del Imperio en el Caribe- y por su relevancia económica, gracias a su vinculación a través de la Ciudad México con el camino de Tierra Adentro, que conectaba con los centros mineros del septentrión novohispano; y el de Acapulco, puerto por el que arribaban al virreinato las mercancías procedentes de Asia, lo que hacía del itinerario México-Veracruz el vector que articulaba la economía colonial.

Sin embargo, pese a su importancia, durante la mayor parte del año las distintas rutas y trayectos ${ }^{2}$ del Camino Real permanecían en condiciones lamentables, lo que afectaba tanto a los habitantes de los pueblos y haciendas vecinos como a los arrieros y comerciantes que lo transitaban, y además provocaba "altos costes de transporte" e incidía en la " 'decadencia' de la agricultura", así como en la "lenta comercialización de la economía rural", ${ }^{3}$ situación que, como lo observó perspicazmente el virrey Revillagigedo, contribuía "muy notablemente a que el comercio no tenga la extensión de que es capaz", ${ }_{4}^{4}$ lo que representaba un lastre para los objetivos de renovación imperial de los monarcas borbones.

${ }^{1}$ De acuerdo con Pérez, el término alude a un "camino de interés público desde el punto de vista oficial. Su ruta, como veremos, puede variar o incluso ser alternativa, pero siempre es una ruta que articula el territorio en su totalidad según las directrices de la economía de la zona. Pérez (2001, p. 45).

${ }^{2}$ Con el devenir de los años, el derrotero entre la capital de la Nueva España y Veracruz quedó establecido por dos rutas definidas a partir del punto por el que cruzaban la Sierra Madre Oriental; una, al norte del Cofre de Perote, "el camino de la Veracruz" y la otra, "el camino nuevo", al sur del Pico de Orizaba. Hay que decir que a diferencia de autores como Rees que miran estas vías como paralelas y redundantes, Valle sostiene que estos caminos tuvieron usos diferentes, que se explican en función de los intereses políticos, económicos y sociales de los distintos actores de la época y de las particularidades de poblamiento de las diversas regiones. Así, la ruta de Veracruz a México por Perote fue utilizada de manera preponderante para la comunicación directa entre el puerto y la capital de la Nueva España y Puebla, en tanto que la de Orizaba, además de comunicar con las ciudades antes mencionadas, facilitaba el tránsito a las regiones del oriente, sur y sureste del territorio novohispano, además de Guatemala, a través de una vasta red de caminos y veredas. Véanse Rees (1976, pp. 14-15); Valle (2007, pp. 437-439); Valle (2007b, p. 8).

${ }^{3}$ Stein y Stein (2005, pp. 270-271).

${ }^{4}$ Florescano (1987, p. 30). 


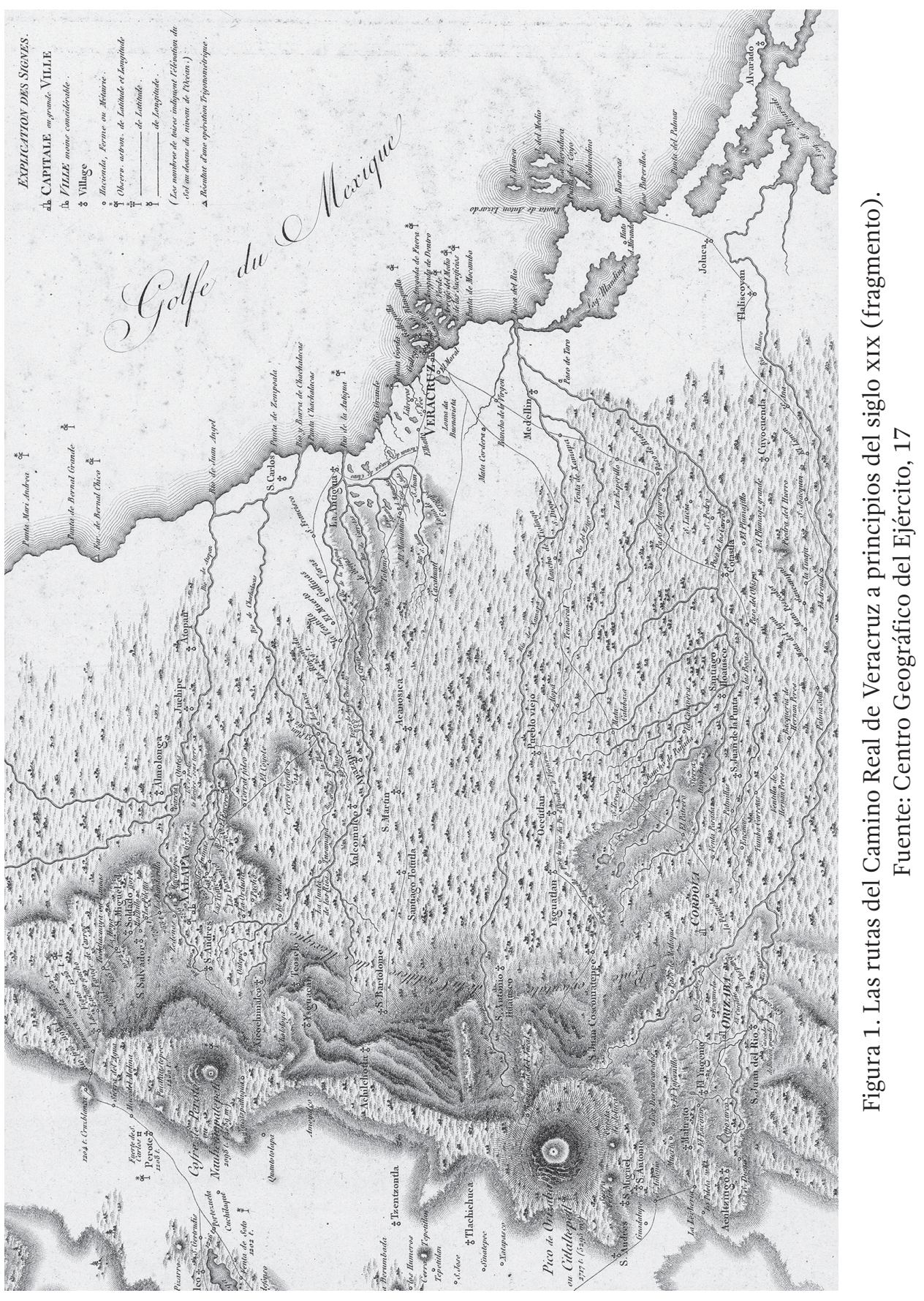


Este escenario se mantuvo inalterado hasta el último tercio del siglo XVIII, cuando el equilibrio de poder entre los distintos actores y grupos oligárquicos de la sociedad novohispana experimentó una profunda transformación como resultado de las innovaciones administrativas y fiscales puestas en operación por Carlos III en el virreinato, las cuales propiciaron el auge de los comerciantes asentados en el puerto de Veracruz en detrimento de los mercaderes agrupados en el Consulado de México, ${ }^{5}$ lo que aunado al interés del gobierno metropolitano por obtener mayores ingresos de la más rentable de sus posesiones en América, confluyó en la necesidad de construir un moderno camino carretero entre la ciudad de México y la plaza veracruzana.

Fue así que, tras perder el monopolio del comercio ultramarino, los comerciantes capitalinos se enfocaron en la construcción de la ruta por Orizaba, en tanto que el Consulado de Veracruz dirigió sus esfuerzos a la edificación de la vía por Xalapa, obra cuyos trabajos pronto adelantaron a los de sus competidores, por lo que en breve tiempo varios tramos del itinerario xalapeño fueron abiertos a la circulación, tal como lo comprobó Alexander von Humboldt, quien a su paso por tierras veracruzanas, dijo que:

El soberbio camino que hace construir el consulado de Veracruz, desde esta ciudad hasta Perote, podrá competir con los del Simplon y del Mont Cenis: es ancho, sólido, y de un declive muy suave. No se ha seguido la delineación del antiguo camino que era muy angosto, empedrado con pórfido de basalto, y que según parece fue construido hacia la mitad del siglo 18: se han evitado cuidadosamente las subidas rápidas; y luego que los carros se substituyan para el transporte de los géneros a las recuas de caballerías, cesarán las quejas contra el ingeniero por haber alargado demasiado el camino. ${ }^{6}$

En consecuencia, ya en los albores de 1810, la ruta por Xalapa era sin duda alguna la más importante de la región y posiblemente de la Nueva España, lo que reafirmó el papel del Camino Real como eje de la vida

${ }^{5}$ Valle sostiene que la puesta en marcha del libre comercio afectó el papel de la ciudad de México como punto de redistribución de los productos que llegaban del exterior, ya que "la continua llegada de navíos a Veracruz había permitido a los comerciantes del interior surtirse directamente en el puerto, en donde adquirían los productos europeos sin los altos recargos que imponían los mercaderes de la capital”. Valle (2000, p. 95).

${ }^{6}$ Humboldt (1822, p. 48). 
económica de la colonia y le dio una relevancia todavía mayor al puerto de Veracruz como punto neurálgico del comercio exterior e interior del virreinato, ${ }^{7}$ lo que a su vez hizo de la provincia veracruzana uno de los escenarios más importantes - y paradójicamente hasta hoy menos abordados- del alzamiento independentista.

\section{LAS PRIMERAS TENTATIVAS PARA LA CONFORMACIÓN DEL CAMINO MILITAR}

\section{El proyecto del Consulado de México}

Ante la virulencia del levantamiento insurgente en El Bajío, y las noticias de las primeras asonadas en la zona de Perote, a principios de mayo de $1811,{ }^{8}$ el gobierno virreinal y el Consulado de México evaluaron la posibilidad de conformar un "camino militar" en el itinerario México-Veracruz, con el fin de mantener a salvo la que, como ya se ha dicho, era la vía de comunicación más importante de la Nueva España. ${ }^{9}$

Dado que la puesta en operación del proyecto demandaba cuantiosos recursos, se sopesaron diversas estrategias para afrontar los gastos, como gravar con un 0.5 todas las cargas que pasaran por las aduanas del reino, idea que finalmente se desechó por las complicaciones que entrañaba su instrumentación y las dificultades para controlar los ingresos que se captaran, debido a la multitud de administraciones mayores y menores dispersas aquí y allá.

${ }^{7}$ Según Fowler: "Es imposible apreciar el puerto de Veracruz sin considerar sus dos caminos a la ciudad de México. Sin esas rutas [...] Veracruz habría sido como Campeche o Tampico. Los caminos otorgaban a Veracruz su importancia estratégica así como su carácter particular. Después de 1804 [...] pensar en Veracruz era pensar en el camino Veracruz-Xalapa [...]. El puerto era lo que era gracias a esa ruta y dio significado al camino y a Xalapa en virtud de su papel predominante como entrada a la Nueva España y, en consecuencia, al comercio de México con España y el mundo”. Fowler (2010, pp. 41-42).

${ }^{8}$ Ortiz (2008, p. 32).

${ }^{9}$ Con este término se designaba "a las direcciones cubiertas de puestos militares que, durante el curso de una campaña o de una serie de operaciones, se establecen a veces, con el objeto de favorecer y mantener expeditas las comunicaciones entre los diversos cuerpos del ejército". Corsini (1849, p. 132). Cabe señalar que para la instrumentación de este tipo de itinerarios por lo general se elegían vías de comunicación que por sus características eran aptas para la circulación de tropas en cualquier temporada, o por lo menos durante la mayor parte del año. Sociedad de Literatos (1832, p. 327). 
Por tanto, se planteó la viabilidad de imponer un arancel del uno por ciento a las introducciones que se hacían por mar en Veracruz, y de dos pesos por arroba a las exportaciones de grana, añil y granilla, con lo que se esperaba obtener unos 180000 pesos al año. Asimismo, se pensó en establecer un impuesto de un peso por barril a los cargamentos de chinguirito que entraran por la plaza veracruzana y a los que pasaran por la aduana de la ciudad de México, con lo que además de conseguir recursos suficientes para la operación del itinerario, se esperaba disminuir "el vicio de ebriedad, que acaso se minorará con esta carga”.

En suma, con estos arbitrios las autoridades virreinales esperaban hacerse de al menos unos 200000 pesos, con los que según sus cálculos, se podrían equipar a entre 1200 y 1500 hombres de todas las armas destinados a la vigilancia de los distintos puntos de la vía, suficientes en teoría para contener el alzamiento, si bien algunos de los involucrados en el plan consideraban que pasaría mucho tiempo antes de que pudiera alcanzarse una paz definitiva, por lo que en su opinión la medida debía hacerse permanente para una mayor seguridad. ${ }^{10}$

A pesar de la gravedad de la situación, esta primera tentativa para el establecimiento del camino militar no fructificó, tal vez por el rechazo de algunos comerciantes criollos y peninsulares a la imposición de nuevos gravámenes en un momento en el que la economía novohispana comenzaba a declinar de forma acelerada y porque las vicisitudes de la guerra distrajeron la atención de las autoridades coloniales.

\section{Los proyectos del gobernador Urrutia y Ciriaco de Llano}

Durante los meses siguientes, la insurrección se extendió a la mayor parte del territorio veracruzano, dándole a los rebeldes la oportunidad de amenazar las principales ciudades de la provincia, como Orizaba, Córdoba y Xalapa, y de interrumpir constantemente la circulación entre esta última población y el puerto de Veracruz, por lo que el gobernador Carlos de Urrutia pensó en emplazar una fortificación de campaña en Plan del Río o La Laja, para lo cual comisionó en abril de 1812 al ingeniero Juan Camargo,

${ }^{10}$ De Antonio de Bassoco al virrey Venegas, 3 de julio de 1811. Archivo General de la Nación (en adelante, AGN), Operaciones de Guerra, vol. 875, exp. 3, ff. 10-12. 
quien tras inspeccionar la zona objetó el proyecto, ya que en su opinión ambas ubicaciones eran vulnerables al ataque de los sublevados. ${ }^{11}$

De esta manera, gracias a la inoperancia de las autoridades virreinales y la indecisión de los estrategas novohispanos, en mayo los insurgentes lograron cortar totalmente la comunicación entre Xalapa, Veracruz y Puebla, por lo que semanas después, el virrey Francisco Javier Venegas le pidió al brigadier Ciriaco de Llano que estudiara la posibilidad de poner en operación un camino militar entre Xalapa y Veracruz.

Por consiguiente, se bosquejó un primer esquema, en el que se proponía ocupar las posiciones de Santa Fe, Puente del Rey y Paso de Ovejas, sitio donde se contemplaba establecer un hospital para socorrer a las tropas que transitaran en el camino y sobre todo, para atender a los regimientos que estaban por llegar de España, ${ }^{12}$ que por su falta de aclimatación se suponía que estarían más expuestos a sufrir los rigores de las altas temperaturas de la región. ${ }^{13}$

Semanas después, ante el cada vez más apabullante dominio de los rebeldes, Llano presentó una segunda propuesta, mucho más elaborada que la anterior, en la que se planteaba establecer un total de entre cinco y seis puestos de control de Xalapa a Veracruz y, además, se consideraba la instalación de una serie de telégrafos de señales u "ópticos"14 para comunicar los distintos puntos del trayecto. ${ }^{15}$

${ }^{11}$ Ortiz (2008, p. 66).

12 De Juan José Soto al virrey Venegas, 5 de agosto de 1812, AGN, Operaciones de Guerra, vol. 992, exp. 19, f. 60 .

13 "Para estos soldados, los insurgentes no eran los peores enemigos a vencer sino el mortífero clima de los litorales [...]. Debemos recordar que el clima y el medio ambiente aunados a la falta de higiene, la deshidratación o las enfermedades tropicales causaban múltiples muertes entre la población." Ortiz (2017, p. 117).

${ }^{14}$ Hay que decir que la primera mención conocida acerca de la posibilidad de instalar un sistema de telegrafía óptica en la Nueva España se debe a Bonifacio de Tosta, quien en una carta dirigida al virrey Venegas, le manifestaba “cuán ventajoso será en este reino tal establecimiento y la utilidad que se sacaría poniendo una línea desde esta capital a Veracruz, pasando por Puebla y Xalapa". En estos momentos el autor está redactando "Señales en el tiempo", artículo dedicado al intento de Bonifacio de Tosta de instalar una línea de telegrafía óptica en la ruta Xalapa-Veracruz.

${ }^{15}$ Esta tecnología que había sido puesta en operación por los franceses en 1794, de acuerdo con el sistema ideado por Claude Chappe, cuyo uso pronto se extendió a otros países como Inglaterra, donde se implantó de acuerdo con el método propuesto por George Murray, y Suecia, donde funcionó con un sistema propio. En cuanto a los telégrafos propuestos por Llano, es posible que éstos se basaran en el diseño puesto en funcionamiento por Hurtado en Cádiz. Olive (2007, pp. 20 y 23). 
En esencia, el plan buscaba articular un "entramado" defensivo entre los distintos puntos del camino con el propósito de que pudieran apoyarse mutuamente; así, las posiciones de Santa $\mathrm{Fe}$ - a tres leguas de distancia de Veracruz- y Paso de Ovejas podrían auxiliarse rápidamente en caso de un ataque rebelde $\mathrm{y}$, a la vez, recibir ayuda de las tropas que se acuartelasen en La Antigua. Con esto, Llano pretendía retomar el control de la zona de Paso de Ovejas, lo que era crucial para bloquear las incursiones que los rebeldes hacían desde Huatusco y San Juan Coscomatepec y vigilar los puntos de La Soledad y San Diego, ubicados en la ruta VeracruzCórdoba-Orizaba.

El resto del itinerario estaría protegido por los destacamentos de Plan del Río - localidad ubicada a seis leguas de Paso de Ovejas- y Cerro Gordo, cuyas tropas podrían actuar en combinación con las que Llano proponía alojar en el trapiche de El Encero, ubicado a corta distancia de Xalapa.

$\mathrm{Al}$ analizar con detenimiento el proyecto, cobra sentido el interés del jefe realista por instrumentar un sistema de telegrafía óptica, ya que la rápida transmisión de noticias entre una guarnición y otra era un factor clave para el éxito del plan, para lo cual era necesario colocar un primer aparato en Santa Fe que enlazara este punto con el puerto de Veracruz, para "que a todas horas sepa el gobierno las ocurrencias que sobrevengan”; uno más entre Santa Fe y Paso de Ovejas, dada la lejanía entre un sitio y otro (seis leguas). Finalmente, se recomendaba poner un tercer telégrafo en Plan del Río, zona que por sus características - alta y despejada- era ideal para comunicar los distintos puestos de la vía.

Ante la falta de instalaciones adecuadas en las localidades elegidas, el jefe realista recomendó que se erigiera una casafuerte de madera en Santa Fe, con capacidad para albergar un destacamento de 25 hombres y que se ocupara una vivienda de cal y canto en Paso de Ovejas, ideal para funcionar como cuartel u hospital militar y que además tenía la ventaja de estar situada a pocos metros de otro inmueble que, por su buena constitución, podía servir como un punto de apoyo para la defensa del edificio principal. ${ }^{16}$

Pese a su minuciosidad, el proyecto de Llano no tuvo la recepción esperada, lo que aunado a la notoria incompetencia de los mandos realistas, le dio a los alzados la oportunidad de controlar la mayor parte del territorio veracruzano. Así, entre julio de 1812 y mayo de 1813, los insurgentes

${ }_{16}$ Plan para el establecimiento del Camino Militar, 1 de septiembre de 1812, AGn, Operaciones de Guerra, vol. 289, exp. 89, ff. 326-327. 


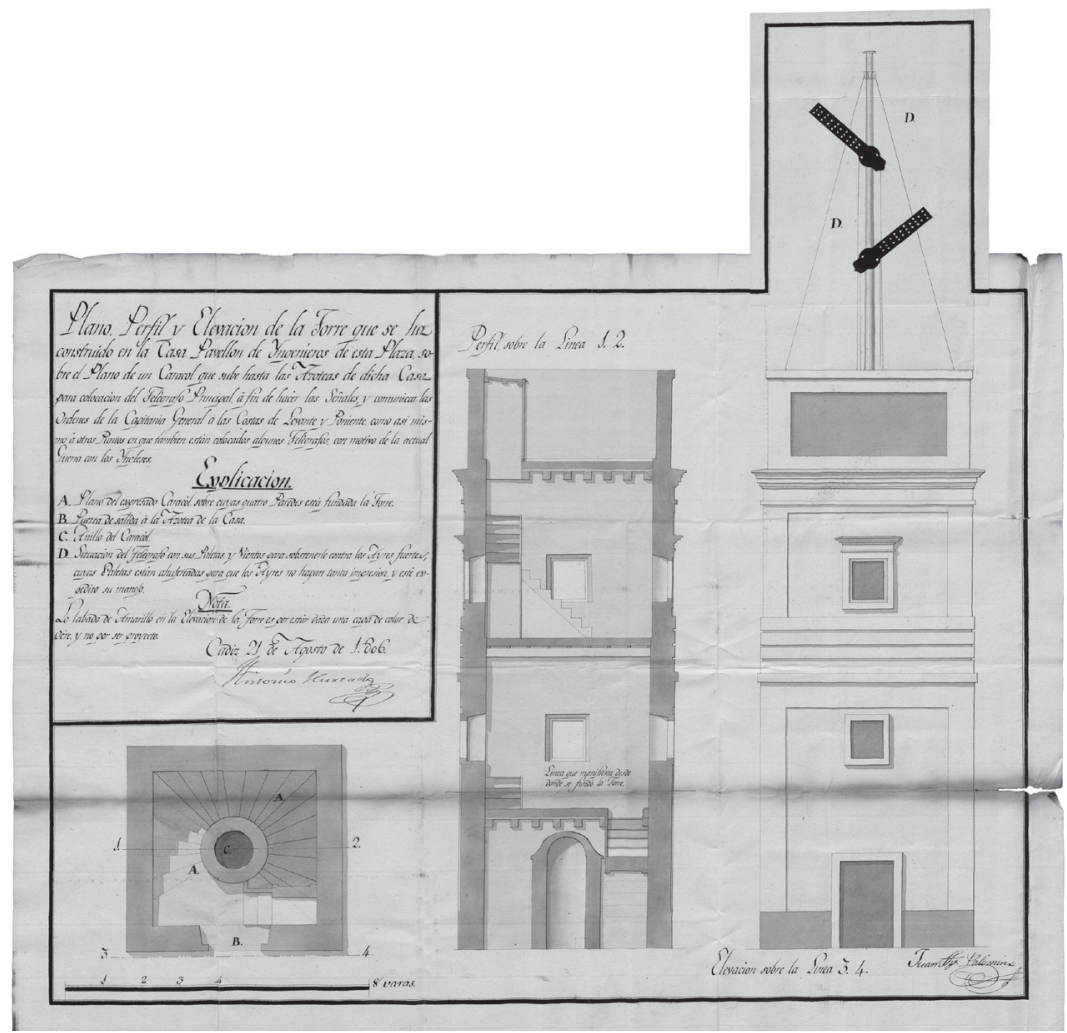

Figura 2. Modelo de las torres y telégrafos ópticos puesto en funcionamiento por el teniente Hurtado en Cádiz. Fuente: Archivo General Militar de Segovia, 50, 535

estrecharon el cerco sobre Veracruz y Xalapa, e incluso, Morelos consiguió tomar Orizaba (29 de octubre), lo que nos da una idea del dominio que ya para entonces ejercían los insurgentes en la provincia.

En este punto, cabe hacer un paréntesis para explicar que no obstante la importancia estratégica del puerto de Veracruz como "llave" de entrada al virreinato, en la región no existía una verdadera estructura de defensa, ${ }^{17}$

${ }^{17}$ De acuerdo con la información disponible, en aquel momento las únicas instalaciones militares existentes en el trayecto Xalapa-Veracruz eran el cuartel de lanceros de La Antigua, construido en 1804 con base en un diseño de Manuel Mascaró; y el presidio de El Órgano, levantado el mismo año para albergar a las tropas y los forzados destinados a las obras del Camino Real. Al respecto, consúltense: De Miguel Constanzó al virrey Iturrigaray, 22 de agosto de 1804, AGN, Indiferente de Guerra, vol. 475A, y De Diego García Conde al prior del Consulado de Veracruz, 14 de julio de 1804, AGN, Consulado, vol. 165, ff. 282-283. 
salvo por el fuerte de San Juan de Ulúa y los baluartes y edificios militares de la plaza veracruzana y las playas cercanas; $y$ al interior, por la dispuesta en Perote, conformada por varias instalaciones situadas alrededor de la fortaleza de San Carlos. ${ }^{18}$ Por tanto, el vasto espacio entre la costa y el altiplano era "tierra de nadie", lo que explica la relativa facilidad con la que los rebeldes habían logrado imponerse.

\section{SEgUNDA LLAMADA: NUEVOS INTENTOS DEL GOBIERNO VIRREINAL PARA CONFORMAR EL CAMINO MILITAR}

\section{Los proyectos de Calleja y Melchor Álvarez}

De esta forma, a fines de 1812 la contienda parecía inclinarse al lado insurgente, sin que Venegas y sus generales atinaran a elaborar un plan de acción que revirtiera el curso de los acontecimientos, ${ }^{19}$ a pesar de la incorporación de varios regimientos peninsulares al ejército virreinal, por lo que en vista de lo desesperado de la situación en enero de 1813 la Regencia designó a Félix María Calleja como jefe político superior de la Nueva España. Su nombramiento era lógico pues sin lugar a dudas era el más capaz de los jefes militares del virreinato.

Ya para entonces Calleja tenía claro que no sería posible vencer a los rebeldes mediante el uso de tácticas militares convencionales, por lo que desde el principio de su gobierno buscó hacer partícipe a toda la sociedad en el esfuerzo contra el alzamiento, para lo cual puso en vigor un reglamento político-militar que no era sino una nueva versión del que como comandante del Ejército del Centro había dado a conocer en Aguascalientes en mayo de $1811 .^{20}$

${ }^{18}$ En esta zona la Corona había conformado un interesante dispositivo bélico como complemento del fuerte de San Carlos, integrado por un cuartel de dragones, dos casamatas (polvorines) y un cuerpo de guardia localizados a poca distancia de la fortaleza, con la idea de que este conjunto actuara como una segunda línea de defensa en caso de que el enemigo venciera las defensas del litoral y tratara de llegar a la ciudad de México.

${ }^{19}$ Consúltense Ortiz (2014, p. 220); Archer (2002b, p. 428).

${ }^{20}$ Reglamento político militar que deberán observar bajo las penas que señala, los pueblos, haciendas y ranchos a quienes se comunique por las autoridades legítimas y respectivas, 5 de marzo de 1813, Real Academia de la Historia, Madrid (en adelante, RAH), 09-01920, ff. 295-298. 
El ordenamiento constaba de un total de 14 artículos que regulaban el modo con el que los habitantes de los pueblos y haciendas debían de hacer frente a las bandas de insurgentes que merodeaban en los alrededores; de éstos, el primero reviste un particular interés, porque en él se especifica que el grueso de las tropas regulares se concentraría en puntos estratégicos, desde donde, "sin necesidad de grandes marchas", acudirían a "destruir las gavillas que por su número den qué temer a los pueblos". ${ }^{21}$

Al parecer, fue con base en esta idea que en abril de 1813, Melchor Álvarez - quien alcanzaría gran notoriedad a lo largo del conflicto y durante los primeros años de México como Estado independiente- ${ }^{22}$ delineó un nuevo plan para la conformación del camino militar entre Veracruz y Xalapa, para lo cual propuso que se fortificaran algunos inmuebles religiosos y civiles, con lo que podrían establecerse las guarniciones "a bajo costo", superando con esto uno de los principales obstáculos que, se infiere, había malogrado los proyectos anteriores. ${ }^{23}$

Álvarez proponía que se ocuparan una vivienda en El Encero, la iglesia de Plan del Río y las instalaciones del portazgo en el Puente del Rey, así como una de las propiedades que el destacado comerciante español Francisco de Arrillaga poseía en Paso de Ovejas. ${ }^{24}$ Además, sugirió acuartelar tropas en San Juan o Tolome y Santa Fe, lugares donde no había edificios adecuados para las guarniciones pero en los que existían suficientes "materiales inmediatos" para construirlos, particularmente en la última ubicación, donde había "mucha madera y palmas". ${ }^{25}$

Empero, las ideas de Álvarez no tuvieron oportunidad de ser puestas en práctica, pues ya para entonces el asunto se había convertido en una cuestión de primera magnitud que, por sus implicaciones, obligó a Calleja a tomar el asunto en sus manos, por lo que apenas unas semanas después, el futuro

${ }^{21}$ Idem.

${ }^{22}$ Hombre de confianza de Calleja, Álvarez fungió como comandante de armas de Xalapa, comandante general de la tercera división del Ejército del Sur y gobernador intendente de Oaxaca. Posteriormente, se unió al Ejército Trigarante, donde fue nombrado jefe del Estado Mayor y después, presidente del Supremo Tribunal de Guerra y Marina, entre otros cargos. Arrioja y Sánchez (2011, pp. 229 y 246-247).

${ }^{23}$ De Melchor Álvarez al virrey Calleja, 27 de abril de 1813, AgN, Historia, vol. 338, f. 25.

${ }^{24}$ Como dato curioso, hay que decir que años más tarde Arrillaga - liberal y simpatizante del alzamiento insurgente- ayudó a Guadalupe Victoria a escapar de sus perseguidores ocultándolo en su hacienda de Paso de Ovejas. Rodríguez (2002, p. 46).

${ }^{25}$ De Melchor Álvarez al virrey Calleja, Xalapa, 27 de abril de 1813, AgN, Historia, vol. 338 , f. 25. 


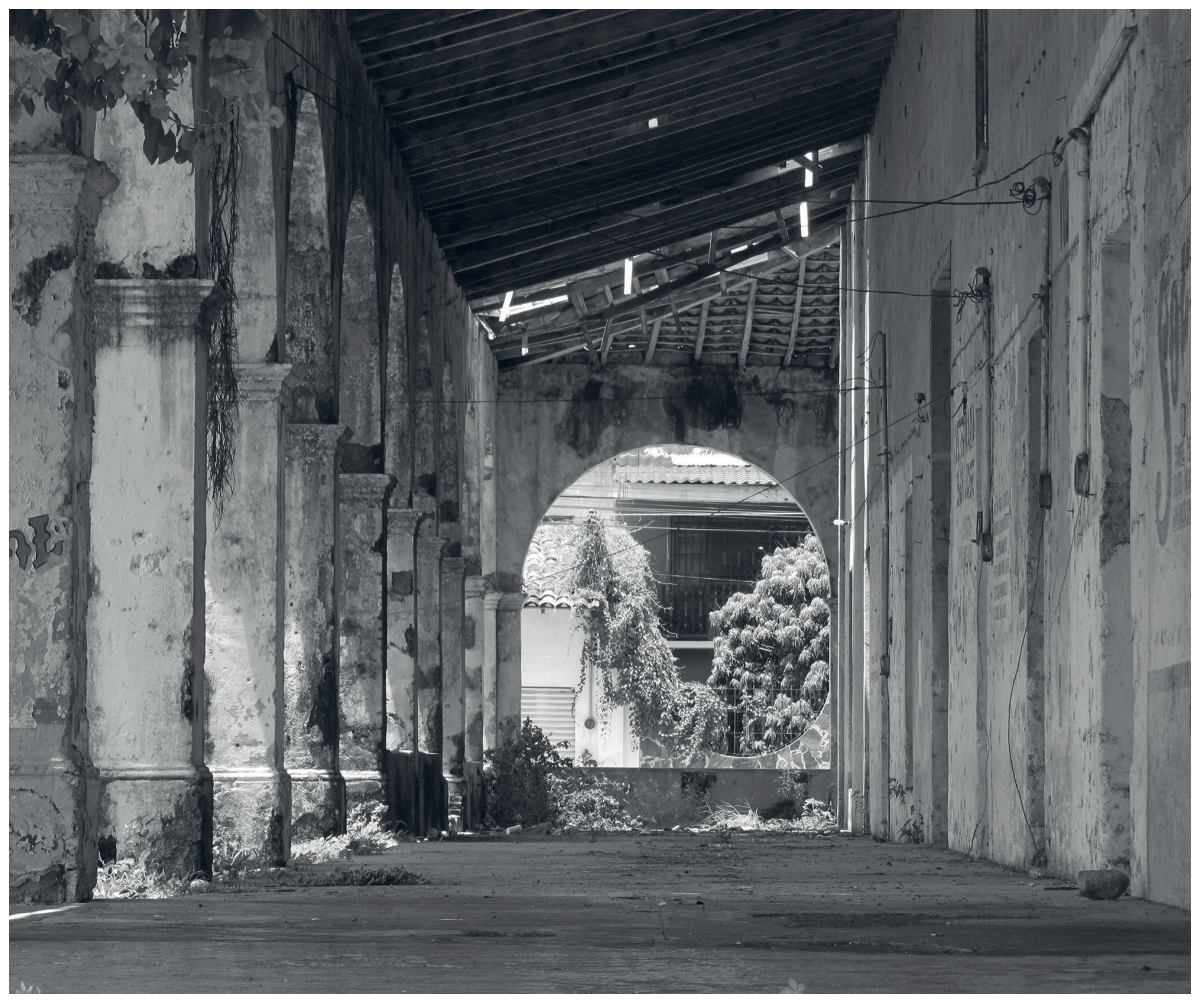

Figura 3. Detalle de Los Portales, inmueble que la sabiduría popular señala como el perteneciente a Francisco de Arrillaga. Fotografía de Sergio Vargas

virrey dispuso la conformación del tan esperado camino militar entre Xalapa y Veracruz, tarea que encomendó al conde de Castro Terreño, general en jefe del Ejército del Sur, y al gobernador de Veracruz, José de Quevedo. ${ }^{26}$

\section{El camino militar de Calleja}

A grandes rasgos, el plan consideraba la creación de un dilatado itinerario desde la fortaleza de San Carlos, en Perote, hasta el puerto de Veracruz, custodiado por puestos de vigilancia en La Joya, Cerro Gordo, Rinconada, Paso de Ovejas y Santa Fe, resguardados a su vez por un total de 920 elementos de infantería y 280 de caballería. Para esto, se contemplaba la edificación

${ }^{26}$ Ortiz (2008, p. 116). 
de varios reductos de planta cuadrangular, con dos pequeños baluartes en los extremos o bien, que se habilitaran inmuebles civiles con las condiciones para ello. En cualquier caso, las guarniciones debían complementarse con foso y estacada. De acuerdo con los cálculos de Manuel Rincón, encargado de las obras, éstas tendrían un costo global de 9400 pesos.

Calleja pretendía que, con el apoyo de esta estructura, pudiera establecerse un convoy que de forma quincenal o mensual saliera de Veracruz a Xalapa o "hasta donde medie la distancia" escoltado por gruesos contingentes de tropas, con el fin de reanudar el envío de la correspondencia y permitir la circulación de personas y mercancías entre ambas poblaciones y con destino a la capital del virreinato. Al salir de Xalapa rumbo a la ciudad de México, la caravana sería protegida por la comandancia de Perote. ${ }^{27}$

Es importante aclarar que para entonces el dominio de los caminos revestía una importancia crucial para ambos bandos, ${ }^{28}$ no sólo desde el punto de vista militar, sino económico, ${ }^{29}$ pues según la información recopilada por el coronel Luis del Águila, los insurgentes le exigían a los mercaderes veracruzanos cinco pesos por cada mula que arribara al puerto y diez por cada una que "subiera" a la capital, tarifa que meses después, gracias al control que tenían sobre ambas rutas del Camino Real, aumentó a tres pesos por carga. Lo anterior provocó el enojo de Calleja, para quien "el escandaloso tráfico que se hace a las inmediaciones de esa ciudad (Veracruz)", le proporcionaba a "los rebeldes grandes recursos para subsistir y continuar haciéndonos la guerra" e inclusive les permitía entrar a la plaza ocultos en los convoyes. ${ }^{30}$

${ }^{27}$ Instrucción para el camino militar de Perote a Veracruz que inmediatamente y venciendo todo obstáculo se establecerá con los importantes fines que expresa, 31 de mayo de 1813, AGN, Historia, vol. 338, exp. 3, ff. 14-16.

${ }^{28}$ Vale la pena señalar que en el bando insurgente el cuidado de los caminos era una cuestión de importancia estratégica, por lo que Morelos ordenó que se arreglaran las vías en las zonas bajo su control, con el propósito de facilitar el paso de la artillería rebelde. Hernán$\operatorname{dez}(2008$, p. 2).

${ }^{29}$ Lo anterior remite a lo que Guzmán ha denominado acertadamente como "economías de guerra”, es decir, el conjunto de acciones y disposiciones puestas en práctica tanto por la Corona y las autoridades virreinales como por los mandos rebeldes para financiar sus actividades y usufructuar el territorio bajo su control. Guzmán (2006, pp. 315-316).

${ }^{30}$ Según los cálculos de Águila, el arreglo era tan beneficioso para los insurrectos que en cierta ocasión obtuvieron 7000 pesos por permitir el tránsito de una caravana de 1000 mulas. Archer (2002a, p. 359). 


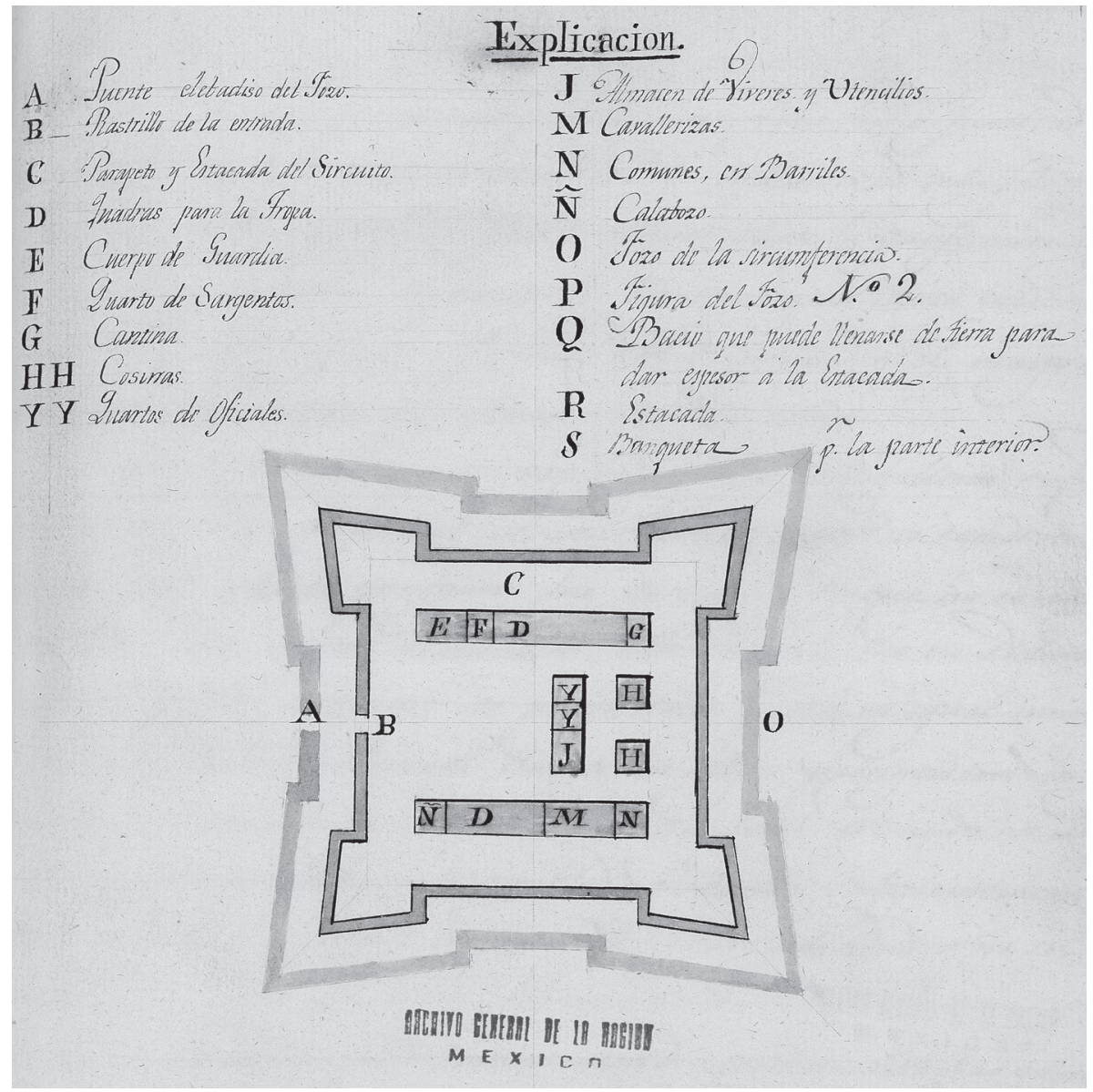

Figura 4. Diseño de la casa fuerte de Santa Fe (fragmento).

Fuente: AGNM, 00353

Sin embargo, Quevedo objetó el plan de Calleja, argumentando en su favor la falta de hombres para cubrir el extenso territorio bajo su mando. En opinión del gobernador, la puesta en marcha del camino militar suponía dejar sin protección los ríos y las costas de Tampico, a través de los cuales los comerciantes de Veracruz mantenían sus operaciones con el interior del país; la costa de Tuxpan, zona que no sólo proveía de granos y carnes a los veracruzanos sino que, además, podía ser utilizada por los rebeldes para traficar con los Estados Unidos; y Tlacotalpan, que de igual manera surtía de víveres a la ciudad y cuya pérdida podía ocasionar que la insurgencia se hiciera con el control de la región desde Acayucan hasta Tabasco. 
Por tanto, para Quevedo lo más conveniente era que una división volante limpiara el camino en torno de Veracruz, tras lo cual, dicha fuerza podría actuar en conjunto con las tropas que se situasen en el Puente del Rey y las de Xalapa para escoltar los correos y las mercancías. ${ }^{31}$

A la vista de los reparos del gobernador y la carencia de recursos, se elaboró una nueva propuesta que en síntesis, únicamente contemplaba la edificación de dos casafuertes: una en Santa Fe y otra en el Puente del Rey, las cuales fungirían como los nodos principales de la ruta en conjunto con la posición de Paso de Ovejas, donde como ya se mencionó había una vivienda apta para acuartelar un nutrido destacamento de tropas e instalar un pequeño sanatorio para atender a los soldados heridos o enfermos de los puntos cercanos. ${ }^{32}$

De esta manera, el ambicioso plan de Calleja poco a poco fue dejado de lado, ya que tanto la comandancia de Puebla como el Ayuntamiento de Xalapa se declararon incapaces de sostener al regimiento de Saboya — principal brazo armado del proyecto-, pero sobre todo, porque en aquel momento la rebelión parecía extinguirse rápidamente, como lo demostraban "el frecuente tránsito de la arriería, las muchas gentes que se presentaban al indulto y el progreso que tenía el establecimiento de compañías urbanas", ${ }^{33}$ por lo que únicamente se autorizó la construcción del cuartel de Paso de Ovejas, ${ }^{34}$ obra que finalmente tampoco se llevó a cabo por las múltiples dificultades que según Quevedo le impedían realizar los trabajos.

En consecuencia, al poco tiempo los insurgentes volvieron a apoderarse del camino, atraídos por las exorbitantes contribuciones que cobraban a los comerciantes y arrieros y que éstos pagaban sin mayores objeciones ante la escasez de víveres y la imposibilidad de trasladarse sin la "protección" de aquéllos, ${ }^{35}$ cuyas filas además habían aumentado de

${ }^{31}$ Ortiz (2008, pp. 119-121).

${ }^{32}$ Manuel Rincón, Para poner remedio a los males que hoy por desgracia tanto nos afligen se hace indispensablemente necesario asentar por principio el establecimiento del camino militar de la plaza de Veracruz a esta villa con arreglo al plan y método que expondré, pues de este modo se evitará afligir a este angustiado vecindario con gravámenes que hoy ya no se puede tolerar en virtud de lo entorpecido de su comercio, 12 de agosto de 1813, AGN, Historia, vol. 338, exp. ff. 46-56.

${ }^{33}$ Ortiz (2008, p. 187).

3415 de diciembre de 1813, AgN, Historia, vol. 338, exp. f. 44.

${ }^{35}$ De acuerdo con Guzmán, para Calleja era evidente que muchos comerciantes, "por codicia o interés, fomentaban con sus negocios al enemigo", proporcionándoles los recursos para sostener sus tropas, por lo que al igual que aquéllos fueron considerados como enemigos de la 
forma notable gracias a la incorporación de un gran número de habitantes de las poblaciones cercanas y los contingentes que habían escapado del sitio de Coscomatepec. ${ }^{36}$

Gracias a esto, los americanos pudieron conformar un efectivo dispositivo de control en la zona, integrado por numerosos enclaves desde los cuales hacían continuas incursiones a los pueblos vecinos y atacaban constantemente a las patrullas realistas que recorrían la vía xalapeña; entre otros, cabe destacar los del cerro del Zopilote, Puente del Rey, El Órgano, Rinconada y Paso San Juan.

Ante este escenario, Calleja ordenó la formación de un cuerpo volante conformado por algunas compañías de granaderos provinciales de Xalapa, apoyadas por las tropas acuarteladas en Veracruz y los alrededores, con el fin de limpiar el camino de rebeldes y desalentar la adición de los pobladores a la insurgencia, así como proteger el paso del convoy y el correo mensual establecido entre ambas ciudades, ${ }^{37}$ con lo que Calleja se proponía también eliminar de un solo golpe las fuentes de recursos de los alzados. ${ }^{38}$

Dominio rebelde de la ruta Xalapa-Veracruz.

El camino militar de Luis del Águila

Como es de suponer, estas disposiciones sólo representaban un pequeño y momentáneo alivio para las tropas imperiales en la provincia, ya que las caravanas realistas eran constantemente hostigadas por las huestes insurgentes, actividad en la que se distinguió el guerrillero José Antonio Martínez, cuyo éxito obligó a Calleja a ordenar a la Aduana de Veracruz que no se expidieran "guías" de viaje para aquellos cargamentos que no fueran escoltados por las tropas del rey. ${ }^{39}$

Además de Martínez, el bastión rebelde del cerro del Zopilote en las cercanías del Puente del Rey constituía otro obstáculo digno de tomarse en

causa realista, "particularmente aquellos arrieros y dueños de efectos que transitaban de Puebla a Veracruz", motivo por el cual estaban expuestos a la confiscación de sus productos. Guzmán (2006, p. 327).

${ }^{36}$ Ortiz (2008, p. 188).

37 Del virrey Calleja al ministro de la Guerra, 31 de octubre de 1814, Archivo General Militar de Madrid (en adelante, AGMM), 5373.21.

38 Archer (2005, p. 260).

${ }^{39}$ Rivera (1869, p. 474). 
cuenta, por lo que a principios de 1815, el coronel Águila propuso variar el recorrido de los convoyes, llevándolos por la vieja ruta que comunicaba el pueblo de La Antigua con Veracruz, con lo que no sólo se reducía el riesgo de sufrir los ataques de los americanos, sino que se acortaba la marcha de forma significativa. Con esta idea, Águila ordenó que se construyera un fortín en el mencionado villorrio, con el propósito de tener un punto de apoyo para el paso de las caravanas. ${ }^{40}$

Pese a estas medidas, la falta de coordinación y las notables diferencias de opinión entre los jefes españoles se reflejaban en continuas recriminaciones y agrias disputas que entorpecían las operaciones de las tropas en el campo de batalla y les impedían responder de forma efectiva a los embates de los insurgentes, que amparados en su mayor movilidad y mejor conocimiento del terreno, en los hechos continuaron como dueños del Camino Real. ${ }^{41}$

Por si fuera poco, las penurias de las campañas provocaban una gran cantidad de deserciones en las huestes del rey, lo que además de privar a los mandos de elementos suficientes para sostener la lucha le daba a los rebeldes la posibilidad de aumentar sus fuerzas, por lo que en abril de 1815 el comandante del cantón de Tlacotalpan Juan Bautista Topete, propuso cambiar nuevamente el itinerario de los convoyes, redirigiéndolos por la ruta de Orizaba, idea que para el gobernador Quevedo era digna de tomarse en cuenta, dada la cada vez más apremiante falta de efectivos y, además, porque esto le "permitiría abandonar el fortín de La Antigua, reducto que [...] consideraba inútil y cuyo cuidado requería que se le dotara de tropas con las que no contaba". ${ }^{42}$

${ }^{40}$ De Luis del Águila al virrey Calleja, 31 de enero de 1815, AGN, Historia, vol. 338, ff. 258-259.

${ }^{41}$ El predominio de los revolucionarios se repetía en otros tramos del itinerario como el México-Puebla, donde Osorno, Serrano y Gómez mantenían en jaque a las tropas del rey; la zona Coscomatepec-Huatusco, controlada por Bravo; y el trayecto de las villas (Córdoba y Orizaba) desde Acultzingo hasta El Chiquihuite, en el que diversos cabecillas obstaculizaban constantemente el paso de los traficantes y atacaban sin descanso a las tropas del rey. Esta situación sólo varió cuando tras la puesta en operación del "camino militar" XalapaVeracruz, el gobierno virreinal instrumentó otras rutas similares; así la vía México-Puebla quedó bajo la protección de los destacamentos del fortín del puente de Texmelucan, el cuartel de Río Frío y la casafuerte de San Fernando de Cordova ( $\mathrm{sic}$ ), en tanto que en la OrizabaCórdoba-Veracruz se construyeron los fortines de la barranca de Villegas, Paso del Macho y San Diego. Al respecto, consúltense: Vargas (2017) y Vargas (2016).

${ }^{42}$ Vargas (2016, pp. 303-304). 


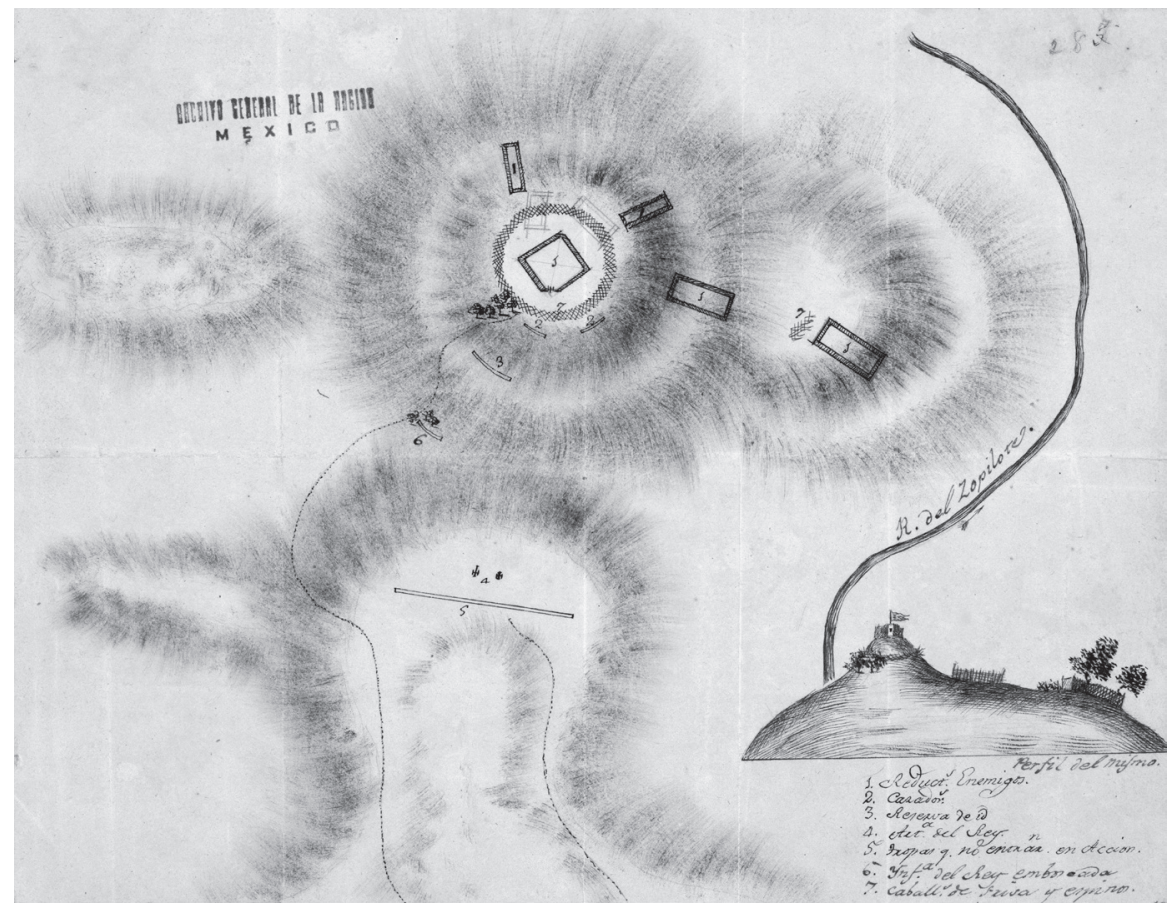

Figura 5. Plano de la posición del cerro del Zopilote. Fuente: AGNM, 00354

\section{GOLPE DE TIMÓN: LA EXPEDICIÓN PACIFICADORA DE 1815}

Mientras tanto en la metrópoli, una vez libre de las ataduras de Napoleón, Fernando VII fue proclamado monarca absoluto, gracias al apoyo del general Elío y de los grupos de poder más conservadores, encabezados por la Iglesia y los oficiales de más alto rango, "aristócratas provenientes en su mayor parte del viejo aparato borbónico”, y el respaldo de los llamados "lealistas", militares quienes más que por rechazo a la ideología liberal, apoyaron al rey porque, ante todo, se consideraban cuerpos profesionales al servicio de la Corona. ${ }^{43}$

Ya en el trono, el nuevo monarca se vio frente a un cúmulo de problemas tras más de diez años de guerra ininterrumpida, entre los que descollaba en primerísimo lugar el inminente rompimiento entre España y sus colonias en América. Si bien inicialmente Fernando VII asumió una actitud

${ }^{43}$ Marchena (2008, p. 152). 
conciliadora -debido quizás a la ingenua idea de que con su regreso los movimientos revolucionarios se extinguirían-, poco a poco fue cambiando de parecer, ante el hecho de que ya para entonces la idea de la separación de España había calado en amplios sectores de las poblaciones americanas y, sobre todo, porque en su mayoría los líderes rebeldes desconocieron la autoridad de la Corona.

En consecuencia, tras meses de análisis y la elaboración de numerosos proyectos, el rey dispuso el envío de una expedición "pacificadora" a América, con el fin de sofocar los diversos movimientos independentistas en el continente. ${ }^{44}$ De acuerdo con Marchena, en esta decisión es posible avizorar distintas motivaciones que en conjunto, pueden explicar una determinación tan arriesgada: recuperar el control de unos territorios que para efectos prácticos se habían emancipado de la autoridad real desde 1810; evitar la alianza de los liberales americanos y españoles, lo que podría derivar en una unión de naciones de tipo federal; y sobre todo, deshacerse de los mandos afectos a la Constitución que en un momento dado podrían "intentar reinstaurarla de nuevo y obligar al rey a cumplirla", tal como efectivamente ocurriría en $1820 .^{45}$

Por otra parte, a los razonamientos de tipo ideológico hay que sumar los de carácter económico - dada la cuantía de los recursos que la metrópoli obtenía de las colonias americanas, especialmente de la Nueva España-, ${ }^{46}$ tales como el interés de grupos como los tratantes de Cádiz, quienes pretendían recuperar el monopolio del comercio con América, y la necesidad de impedir el lucrativo comercio que los ingleses hacían en el Nuevo Mundo. A éstas, podemos agregar la necesidad de ocupar a las numerosas tropas que tras la expulsión de los franceses habían quedado ociosas en el reino. ${ }^{47}$

A la vista de la delicada situación que afrontaban las tropas imperiales en el virreinato mexicano y la manifiesta incapacidad de los comandantes

${ }^{44}$ Martiré (2012, pp. 116-119).

${ }^{45}$ Los temores de El Deseado no carecían de fundamentos, pues varios destacados militares liberales habían manifestado en las Cortes y en distintos ámbitos su rechazo a la vía militar para solucionar la cuestión americana, propugnando en cambio la negociación y el acuerdo con los independentistas del Nuevo Mundo. Para Marchena, fue esta combinación de liberalismo, constitucionalismo y negociación presente en la mayor parte de la oficialidad liberal lo que determinó su envío a América. Marchena (2008, pp. 152 y 155-157).

${ }^{46}$ Para una mejor comprensión del papel del virreinato novohispano en el conjunto de la economía imperial a fines del siglo XVIII, se recomienda la lectura de Marichal y Souto (2012).

${ }^{47}$ Martiré (2012, pp. 113 y 119-120). 
novohispanos para recuperar el dominio del Camino Real, el alto mando dispuso el envío de un importante número de tropas a las órdenes de Fernando Miyares y Mancebo, militar criollo que tenía una dilatada experiencia guerrera debido a su participación en las campañas contra la Convención Francesa (1794-1795) y durante la invasión napoleónica a la península, conflicto en el que se distinguió en numerosas acciones frente a la Grande Armée.48

La expedición de Fernando Miyares, 1815-1816

Un aspecto que conviene resaltar es que a diferencia de las fuerzas enviadas a América en los años previos (1811-1814), integradas en su mayor parte por elementos "bisoños, con una muy deficiente instrucción y poca idea de disciplina", reclutados de entre la multitud de "desocupados en el campo y en las ciudades que encontraban en el alistamiento casi la única forma de subsistir" ${ }^{49}$ los regimientos que viajaron con Miyares estaban integrados por veteranos de la guerra de Independencia española, que se pensaba "tanto por su número como por su calidad no [podían] encontrar oposición de ninguna especie". ${ }^{0}$

De esta manera, Miyares arribó a Veracruz el 18 de junio de 1815, acompañado de cerca de 2000 hombres de los regimientos de Órdenes Militares y Navarra, que pese al largo viaje se encontraban en buen estado de salud, por lo que apenas dos días después se pusieron en marcha rumbo a Xalapa, a donde llegaron sin demasiadas complicaciones el día 26 del mismo mes. ${ }^{51}$

Así, entre agosto y diciembre el venezolano se dedicó a "limpiar" de rebeldes el itinerario, dándose tiempo incluso para efectuar numerosas

${ }^{48}$ Fernando Miyares y Mancebo nació en Caracas, Venezuela, alrededor de 1779 y murió el 26 de septiembre de 1821, probablemente en Badajoz, España. Fue hijo del destacado mariscal de campo cubano Fernando Antonio Vicente Miyares Pérez, quien a lo largo de 40 años desempeñó diversos cargos al servicio del Imperio español, durante los que fue reconocido por su "eficacia, buen orden, celo y habilidad", cualidades que según parece heredó a su vástago, quien se inició en la carrera de las armas en 1792, en la que su eficiencia y capacidad le hicieron ascender de cadete a brigadier y en la que, como se verá más adelante, adquirió vastos conocimientos de la teoría y la práctica de la ingeniería militar. Hoja de servicio de Fernando Miyares y Mancebo, Archivo General Militar de Segovia (en adelante, AGMs), secc. 1, leg. 3216, carpeta 1; y Berbesí (2014).

${ }^{49}$ Marchena (2008, p. 207).

${ }^{50}$ De Xavier Abadía a Fernando Miyares, 7 de abril de 1815, AGN, Historia, vol. 338, f. 486.

${ }^{51}$ De José de Quevedo al secretario del Despacho Universal de Indias, 30 de junio de 1815, AGMM, 5373.25. 
expediciones en la vía por Orizaba y en la zona entre Veracruz y Puebla, mientras que en paralelo se ocupaba de la puesta en operación del tan largamente esperado camino militar entre Xalapa y Veracruz, acciones que, como se verá más adelante, rápidamente le permitieron lograr lo que hasta entonces había sido una quimera: dejar el camino expedito para la circulación de personas y mercancías. ${ }^{52}$

\section{Las fortificaciones realistas del Camino Real de Veracruz}

Tal como lo especificaban sus instrucciones, desde su llegada a tierras veracruzanas Miyares se dedicó a estudiar la manera de contrarrestar el domino que los rebeldes ejercían en el Camino Real, tras lo cual elaboró un plan en el que proponía ocupar los puntos de El Encero, Cerro Gordo, Plan del Río, El Órgano, Cuesta de la Calera y el Puente del Rey, así como los de Santa Fe, el puente de San Juan y La Antigua; sin embargo, luego de un análisis más detallado de la cuestión, decidió que sólo se establecieran los destacamentos de El Encero, Plan del Río, Puente del Rey y La Antigua, ya que en las demás posiciones el agua escaseaba y era prácticamente imposible proveer a las guarniciones de forma adecuada.

Enterado de que los torrenciales aguaceros que caían en época de lluvias podían inutilizar el último tramo de la ruta principal, el venezolano resolvió ocupar también las posiciones de San Juan y los llanos de Santa Fe. Si bien en un primer momento Miyares había calculado que se requeriría de unos 800 hombres para cubrir todos los puestos, luego consideró que únicamente se necesitaría la mitad de dicho número, a condición de que los bastiones proyectados se edificaran de acuerdo con el sistema ideado por el ingeniero francés Marco Renato Montalembert, bajo cuyas premisas había hecho construir el fortín de Órdenes Militares en Plan del Río. ${ }^{53}$

52 Hay que señalar que no obstante sus logros el propio Miyares era consciente de que la victoria definitiva para el ejército imperial estaba lejos de alcanzarse, no sólo por la tozuda oposición de Guadalupe Victoria y otros jefes rebeldes, sino por las desastrosas condiciones en las que se encontraba el ejército del rey, diezmado tanto por los ataques de los insurgentes como por las enfermedades y el mortífero clima de la región. Así, ante la escasez de hombres, los contingentes realistas llegaron a estar conformados por elementos pertenecientes a "11 o más distintos cuerpos" lo que en palabras del venezolano era "militarmente visto bien monstruoso". Archer (2002b, p. 433).

${ }^{53}$ De Fernando Miyares al virrey Calleja, 18 de febrero de 1816, AGMM, 5373.28. 
$\mathrm{Al}$ respecto, cabe señalar que desde el último tercio del siglo Xvir la inmensa mayoría de las fortificaciones europeas se construían bajo la égida de los principios de Vauban, célebre ingeniero francés que gracias a su experiencia en distintos asedios elucubró nuevas estrategias de ataque, y después ante la urgencia de proteger a su país, innovó los métodos de defensa, logrando con esto restablecer el equilibrio entre ambas caras de la poliorcética. ${ }^{54}$

Empero, en la segunda mitad del siglo Xvin Montalembert juzgó, para "asombro [incluso] de los innovadores más atrevidos, [como] imperfectos y aun perjudiciales”, las ideas de Vauban, lo que suscitó una encendida polémica entre sus contemporáneos, pues hasta entonces las ideas de éste habían sido consideradas como "la perfección del arte" de la fortificación. $^{55}$

Según Junquera, el principio que sostenía los postulados teóricos de Montalembert era el de concentrar "grandes masas en los puntos decisivos", es decir, acumular una gran cantidad de piezas de artillería colocadas estratégicamente, impidiendo de esta forma que el enemigo pudiera establecer baterías de brecha y contrabaterías, o que pudiera hacer uso de éstas en caso de haberlas construido.

Consciente de que para sacar el mayor provecho de la artillería disponible era indispensable protegerla del fuego del enemigo, y de la necesidad de resguardar a las tropas y las municiones, Montalembert le otorgó un gran protagonismo a las casamatas, convirtiéndolas en el elemento principal de sus fortificaciones, desechando el uso del baluarte, que como es de suponer era el componente sustancial de la fortificación abaluartada. ${ }^{56}$

Montalembert propuso tres sistemas de fortificación basados en sus principios: el atenazado, en el que los ángulos entrantes son rectos, para que el flanqueo recíproco sea más eficaz; el poligonal, en el que se confía la defensa del frente a una gran caponera situada en el foso principal dotada de un gran número de piezas de artillería; y el circular, que tenía como característica principal la de abarcar la mayor cantidad de espacio con el menor perímetro. ${ }^{57}$

\footnotetext{
${ }^{54}$ Junquera (1866, pp. 8-9).

55 Bernáldez (1860, pp. 10-11).

56 Junquera (1866, pp. 13-14).

57 Junquera (1866, p. 54).
} 


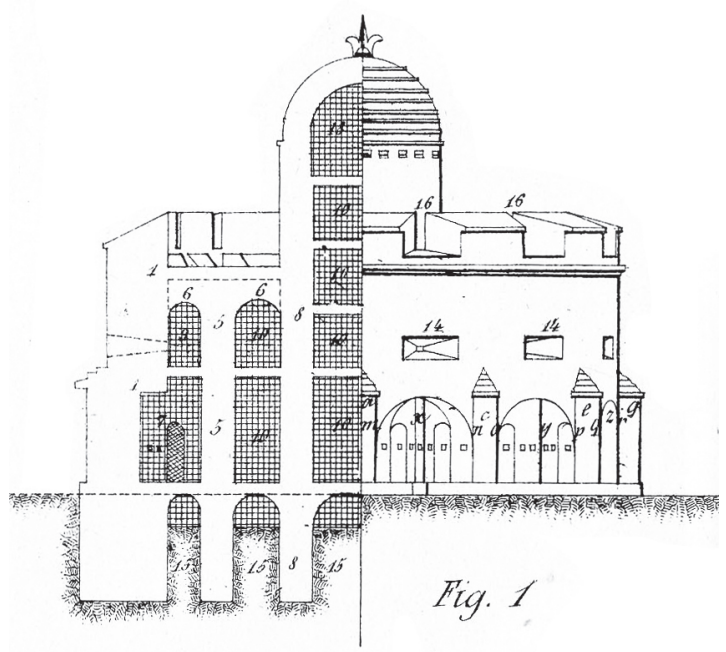

Figura 6. Esquema de una fortificación tipo Montalembert. Fuente: I. Junquera y Sánchez (1866). Elementos de fortificación moderna. Madrid: Imprenta y Estereotipia de M. Rivadeneyra

Aun cuando en un principio las ideas de Montalembert fueron enérgicamente rechazadas por la mayor parte de sus colegas ${ }^{58}$ - quizá por no ser como muchos de ellos miembro del Cuerpo de Ingenieros de Francia-, éstas poco a poco fueron ganando aceptación, al grado tal que Carnot, quien inicialmente las había considerado absurdas, adoptó después varias de sus propuestas, e incluso le escribió para disculparse por haberlo criticado, diciéndole: "Dejad al tiempo madurar las ideas; que os baste por ahora el convencimiento de que vuestra teoría será muy pronto la base de nuestro sistema defensivo". 59

Hay que señalar que debido a las reticencias iniciales, la obra de Montalembert tuvo un impacto mayor en Alemania, donde desde inicios del siglo XIX se construyeron numerosas obras de defensa acordes con las ideas del ingeniero francés, dando origen a lo que, paradójicamente se conoció como

58 Incluso un experto como el general de ingenieros Fourcroy llegó a declarar que "toda proposición que tendiera a introducir mejoras en el arte (de la fortificación) era una prueba cierta de la ignorancia de su autor, pues nada se hallaría mejor que el método de Cormontaigne", autor que había corregido algunas de las imperfecciones atribuidas al sistema de Vauban. Bernáldez (1860, p. 14).

${ }^{59}$ Idem. 
"escuela de fortificación alemana". ${ }^{60}$ Cabe suponer que gracias a su experiencia en las guerras contra los franceses y su estancia en el Cuerpo de Ingenieros, Miyares tuvo la oportunidad de conocer de primera mano las innovaciones planteadas por Montalembert, mismas que, puede inferirse, consideró que se adaptaban plenamente al tipo de conflagración que se desarrollaba en la Nueva España.

Una vez aceptado el plan de Miyares, se dio inicio a la construcción de los reductos, si bien hasta donde se sabe, únicamente el fortín de Órdenes Militares (Plan del Río) se hizo de acuerdo con los postulados de Montalembert, por lo que quizá, se trate del único bastión en Nueva España -y tal vez en América- construido según el método del ingeniero francés.

Así, el fortín de El Encero se construyó en una venta cercana a la hacienda del mismo nombre, modificando las piezas del inmueble para que albergara una guarnición de 20 hombres, agregándole además un medio baluarte y dos parapetos. La posición se reforzó habilitando como bastión el horno contiguo, con el fin de que ambos puestos se defendieran mutuamente.

En las inmediaciones del Puente del Rey, Miyares erigió dos reductos, el primero, tomando como base las defensas hechas por los insurgentes - conjunto al que dio el nombre de Atalaya de la Concepción-, las cuales perfeccionó con la construcción de un parapeto, un foso y una torre para la colocación de un telégrafo.

En el cerro opuesto, se dispuso la edificación de otro bastión, al que el venezolano nombró "Fernando VII", con el propósito de que éste y la atalaya se apoyasen uno al otro. Este fortín era un recinto simple, que Miyares consideraba provisional, pues en su opinión la planta del edificio debía ampliarse lo suficiente para levantar en su interior algunos barrancones para la tropa y un almacén de municiones.

En cuanto a la zona de La Antigua la información disponible resulta contradictoria, ya que Miyares refiere la existencia de un reducto cuya construcción adjudicó al líder rebelde "Chino" Claudio; no obstante, como ya se dijo, un año antes el coronel realista Luis del Águila había construido un fortín en esta área, por lo que es posible que se trate del mismo inmueble que menciona el venezolano, como puede inferirse por la acertada hechura del edificio, que Miyares denomina como "la mejor obra que he visto de los rebeldes".

${ }^{60}$ Bernáldez (1860, p. 13). 


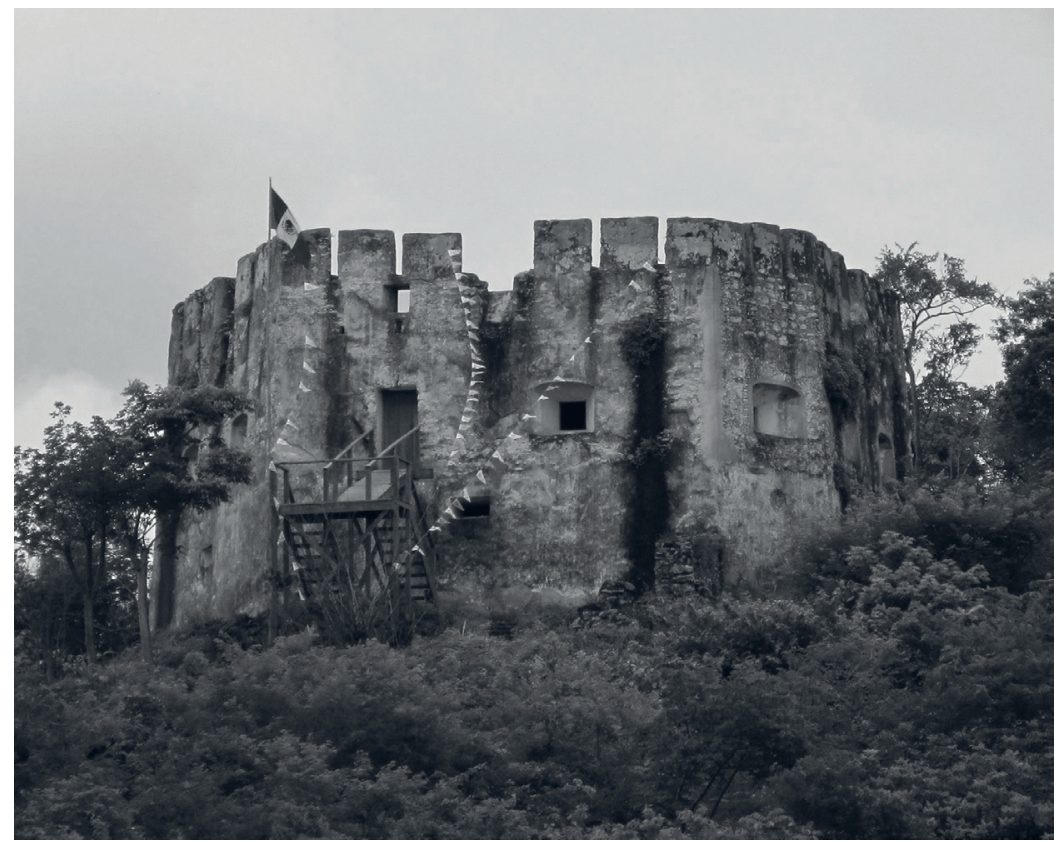

Figura 7. Fortín de Órdenes Militares de Plan del Río. Fotografía de Sergio Vargas

Cabe mencionar que pese a su buena manufactura, para Miyares este bastión era poco útil, ya que estaba ubicado en la confluencia de los ríos de La Antigua y San Juan, por lo que corría el riesgo de inundarse en época de lluvias y además, debido a que por su colocación podía ser atacado con cierta facilidad desde la orilla opuesta del río San Juan.

Por lo tanto, el jefe realista sugirió que se construyera otro reducto ${ }^{61}$ en el margen derecho del río La Antigua, en un promontorio ubicado a unas

${ }^{61}$ En diversos planos elaborados según parece tras la partida de Miyares se asienta la existencia de dos bastiones en las cercanías de La Antigua, por lo que es válido suponer que la construcción del reducto propuesto por el venezolano sí se llevó a cabo. Al respecto consúltense: Plano geográfico de una parte de la provincia de Veracruz, hasta Perote correspondiente a la Puebla: con expresión del Camino Real para México, con las demás trochas y veredas, así de ruedas como de herradura, por donde se hace el comercio a las villas y demás puntos indicados en el plano, 1816, RAH, 20101000135; Carta de una parte del estado de Veracruz comprendida entre los $18^{\circ} 18^{\prime}$ y los $19^{\circ} 47^{\prime}$ de latitud, y 98 grados y $99^{\circ} 35^{\prime}$ de longitud al occidente de París, s/f, Mapoteca Orozco y Berra, Ciudad de México (en adelante, моYв), 47-OYB-7261-A; y Plano geográfico que demuestra una parte del estado de Veracruz y sus costas comprendidas entre Palma Sola y Alvarado, s/f, моув, 53-OYB-7261-A 
cuantas varas, paraje que en su opinión estaba a salvo de la subida de las aguas y desde donde se dominaban los alrededores con el fusil o con el cañón. Por si fuera poco, este sitio tenía la ventaja de que desde ahí podía avistarse la atalaya de La Concepción, "circunstancia interesantísima para el establecimiento de la línea telegráfica”, ${ }^{62}$ tarea que le había sido comisionada de forma expresa por el alto mando. ${ }^{63}$

Para la edificación del bastión, que en su opinión debía hacerse de figura pentagonal, Miyares propuso que se aprovecharan "los escombros del destruido pueblo de La Antigua”, utilizando como mano de obra la de los forzados que se hallaban en Veracruz. ${ }^{64}$ En total, en la construcción de los fortines del trayecto Xalapa-Veracruz, se invirtieron 12463 pesos dos reales seis granos, monto del cual casi la mitad se destinó al pago de los zapadores que participaron en las obras y la compra de utensilios y herramientas. ${ }^{65}$

Más allá de las novedades "técnicas" instrumentadas por Miyares, son varias las causas que explican el notable éxito conseguido por éste en su labor en comparación con lo hecho por los comandantes que lo precedieron: en primer término, la autoridad y la libertad que le confirió Calleja para operar como mejor le pareciera; su habilidad para atraerse las simpatías del ayuntamiento de Xalapa, principal sostén económico del ejército virreinal en la zona; su pericia en el mando de las tropas a su servicio, y "la clemencia [...] cualidad que distinguió a Miyares de los demás jefes realistas, quien no solamente no derramó sangre, sino que guardaba con las gentes de los campos consideraciones hasta entonces desusadas". ${ }^{66}$

${ }^{62}$ Esta tecnología había demostrado ampliamente su utilidad en Europa al favorecer el éxito de los ejércitos napoleónicos y durante el sitio de Cádiz, ocurrido tras el desastre de Trafalgar, por lo que no es de extrañar que el alto mando considerara de sumo interés la colocación de una línea de telegrafía óptica en el Camino Real, la cual inicialmente se pensó en instalar en el cerro de Macuiltépetl, Cerro Gordo, Plan del Río y la Cuesta de la Calera, pero que luego se decidió colocar en la Atalaya de la Concepción, La Antigua, Loma Criolla y el fuerte de San Juan de Ulúa. Con dicho fin, el venezolano dispuso la construcción de cuatro aparatos que finalmente no se instalaron. De Fernando Miyares a José Dávila, Veracruz, 8 de abril de 1816, AGMм, 5373.30.

${ }^{63}$ De Xavier Abadía a Fernando Miyares, 7 de abril de 1815, AGN, Historia, vol. 338, f. 486v.

${ }^{64}$ De Fernando Miyares a José Dávila, 8 de abril de 1816, AGMm, 5373.30.

${ }^{65}$ De Manuel Rincón al virrey Calleja, 6 de septiembre de 1816, Archivo General de Indias (en adelante, AGI), México, 1322.

${ }^{66}$ Rivera (1869, pp. 515-516). A los anteriores, cabe agregar otro factor no menos importante y quizá más decisivo: la falta de coordinación entre los distintos cabecillas que operaban en la región de Veracruz, quienes pocas veces actuaron de forma conjunta, lo que dificultaba la organización de acciones más efectivas, pese a los denodados esfuerzos de 
Sin embargo, no todo eran buenas noticias para el venezolano, quien en diciembre de 1815 fue nombrado jefe político y militar e intendente de la provincia de Veracruz, ${ }^{67}$ responsabilidades que lo obligaban a atender un sinnúmero de asuntos de toda clase que se sumaban a las pesadas tareas propias de su profesión, y a las fatigas y la tensión causadas por los constantes enfrentamientos contra los rebeldes. Por si fuera poco, Miyares sufría los estragos del terrible clima de Veracruz, que agravaba las dolencias que padecía desde que en septiembre de ese año había recibido un fuerte golpe en el pecho en el curso de un combate contra los insurgentes en las inmediaciones de Tlacolulan. ${ }^{68}$

A todo lo anterior, hay que agregar el hecho de que durante su estancia, Miyares había tenido tiempo suficiente para evaluar las aptitudes de buena parte de la oficialidad novohispana, análisis cuyos resultados no eran nada favorables, pues descubrían muchos de los vicios, errores y abusos en los que incurría la mayoría de los jefes realistas cuya mala actuación perjudicaba de manera determinante los esfuerzos de la Corona para terminar con la rebelión.

Por tanto, en febrero de 1816 Miyares recomendó una reforma general del ejército virreinal, con el propósito de reestructurar los distintos cuerpos que lo componían con los mejores hombres disponibles, repatriando a España a todos los oficiales que no fueran necesarios, "deshaciéndose de los que pueda haber que no estén en estado de servir por sus achaques, edad avanzada o ineptitud, sin pararse mucho en las solicitudes que los que se hallen en cualquiera de estos tres casos hagan por permanecer en el servicio, por las consecuencias que es bien obvio el deducir".

En su informe, el venezolano lamentaba que a pesar de lo dilatado del conflicto, hasta ese momento no se había elaborado un plan general de operaciones que guiara la actuación de los distintos mandos - lo que puede

Guadalupe Victoria por cohesionar y dotar de una organización operativa -y sobre todo de un ideario político- a las fuerzas rebeldes. En este sentido, es posible afirmar sin duda alguna que la muerte de Morelos, acaecida el 22 de diciembre de 1815, representó un duro golpe para la insurgencia pues, a partir de entonces, el movimiento careció del liderazgo indiscutible del cura de Carácuaro, lo que se tradujo en una serie de enfrentamientos entre el resto de los jefes rebeldes que buscaban hacerse con el mando. En cuanto a Victoria, cabe señalar que no sólo se esforzó por estructurar a la insurgencia en Veracruz, sino que también buscó la manera de conformar un gobierno "nacional" provisional en concierto con Vicente Guerrero y Ramón Sesma, iniciativa que finalmente no prosperó. Saucedo (2014, pp. 384-385).

${ }^{67}$ De Fernando Miyares al virrey Calleja, 18 de diciembre de 1815, AGMM, 5373.30.

${ }^{68}$ Ortiz (2008, p. 222). 


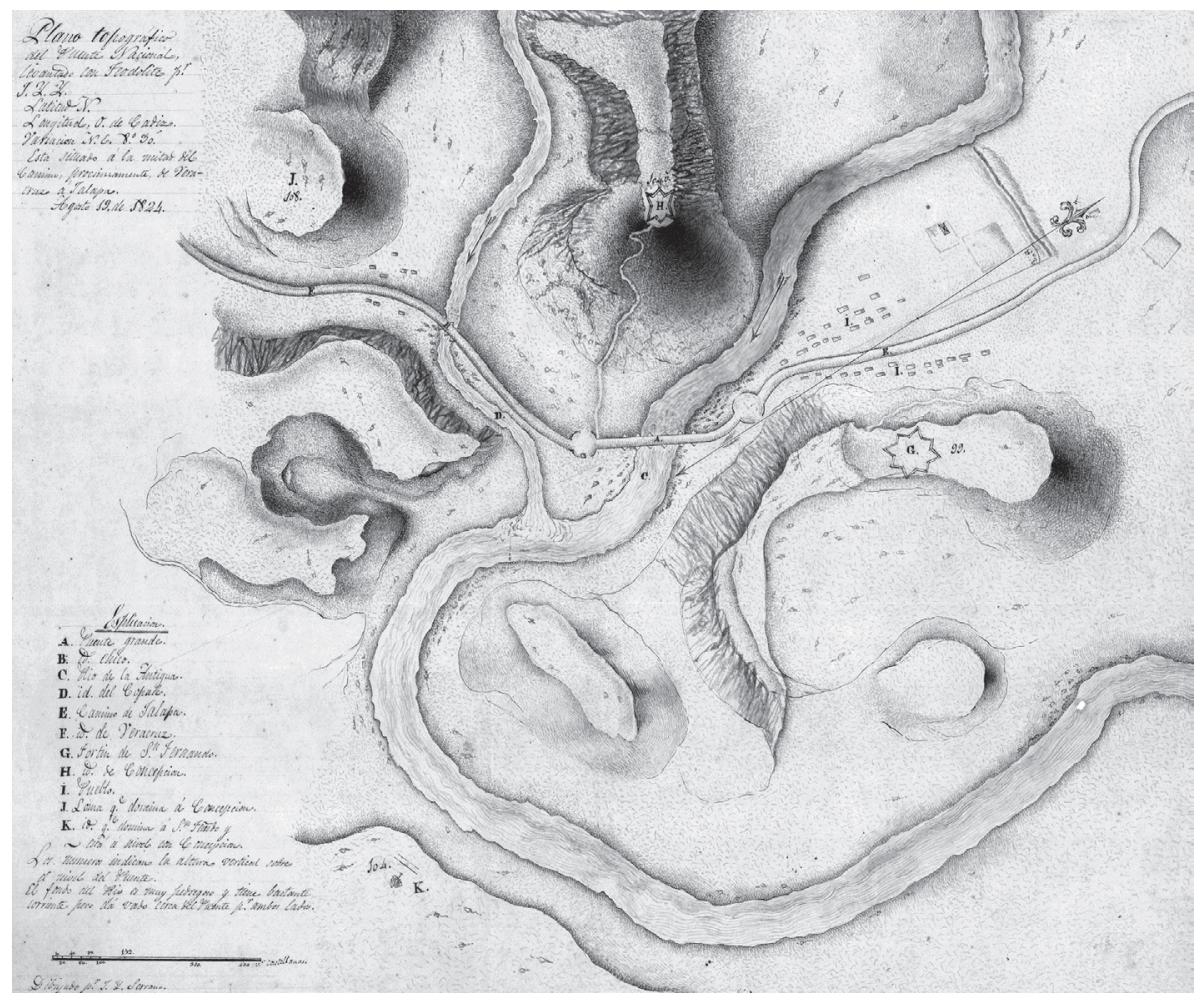

Figura 8. Plano de la posición de Puente del Rey, donde se aprecian las fortificaciones situadas a ambos lados del camino. Fuente: Mapoteca Orozco y Berra, 6507-CGE-7261-A

interpretarse como un velado reproche al desempeño de Calleja-, por lo que según él cada jefe actuaba de acuerdo con sus propias ideas y conveniencias, lo que limitaba el impacto de los triunfos conseguidos por las fuerzas españolas, justo cuando se estaba tan cerca de conseguir la victoria final. ${ }^{69}$

Aunque no se tiene constancia de las reacciones del estamento militar a las fuertes críticas hechas por Miyares, cabe inferir que, de conocerlas, seguramente causaron un profundo malestar entre los comandantes novohispanos, quienes a su vez miraban la exitosa actuación del venezolano con recelo, sobre

${ }^{69}$ Ortiz (2008, pp. 235-237). Hay que decir que Miyares no fue el único que criticó la falta de capacidad de las autoridades virreinales para exterminar a la insurgencia, pues tanto el obispo de Michoacán, Manuel Abad y Queipo, como el de Puebla, Antonio Joaquín Pérez, se expresaron en términos similares, incluso acerca del desempeño del propio conde de Calderón. Ortiz (2017, pp. 173-176). 
todo al contrastarla con los mediocres resultados logrados por ellos. ${ }^{70}$ Como haya sido, lo cierto es que, a las pocas semanas de haber presentado su evaluación, Miyares entregó el mando de la plaza de Veracruz a José Dávila. ${ }^{71}$

A su salida, las obras del camino militar quedaron a cargo del teniente coronel Manuel Rincón, personaje que junto con su hermano José había colaborado estrechamente con el venezolano, tanto en sus campañas militares como en la construcción de las fortificaciones que se hicieron durante su corta estancia en tierras veracruzanas. ${ }^{72}$

Hay que mencionar que pese a los halagüeños pronósticos de Miyares acerca de la durabilidad de los edificios (véase anexo), al poco tiempo los comandantes de las guarniciones debieron solicitar de forma urgente recursos para la reparación de los inmuebles, pues éstos presentaban daños estructurales ocasionados por las continuas lluvias que asolaban la región y quizá, por la premura con la que fueron edificados. ${ }^{73}$

\section{EPÍLOGO}

Meses después, el nuevo virrey Juan José Ruiz de Apodaca y Eliza inspeccionó los puestos militares dejados por Miyares, con el fin de constatar su estado y evaluar su utilidad, tras lo cual propuso que se construyeran otros bastiones en la costa y en los puntos intermedios de la ruta, concretamente en Punta Gorda (tramo Veracruz-La Antigua), Jalcomulco (La AntiguaPuente del Rey), Rinconada (Puente del Rey-Plan del Río) y Cerro Gordo (Plan del Río-El Encero). Según el virrey, el costo de cada uno de estos inmuebles sería de 500 pesos.

En relación con los fortines existentes (La Antigua, Fernando VII, El Encero), Apodaca informó que éstos necesitaban diversas reparaciones, ya que carecían de las instalaciones necesarias para la tropa, o bien requerían

${ }^{70}$ Ya para entonces la relación de Miyares con sus colegas no era la mejor pues, según Alamán, el venezolano estaba muy "disgustado por la rivalidad que notaba en el mismo virrey y en otros jefes, nacida acaso de la superioridad de los conocimientos de aquél”, si bien Archer sostiene que Calleja reconocía sin ambages el talento "guerrero" de Miyares, al grado tal que cuando éste, forzado por sus lesiones, decidió abandonar el virreinato, "casi [le] imploró [...] que reconsiderara su decisión y esperara más tiempo para recobrar la salud”. Revísense Alamán (1849, p. 371); Archer (2008, p. 214).

${ }^{71}$ De Fernando Miyares a José Dávila, 8 de abril de 1816, AGMm, 5373.30.

${ }^{72}$ De Manuel Rincón al virrey Calleja, 6 de septiembre de 1816, AGI, México, 1322.

${ }^{73}$ Idem. 
de algunas adecuaciones para hacerlos más funcionales, gastos que el virrey propuso que fueran cubiertos a partes iguales por la Corona, los comerciantes de Veracruz y los vecinos de la zona.

Mención aparte merece la atalaya de La Concepción, punto que en opinión de Apodaca debía ser abandonado y destruido, ya que era "completamente inútil y embarazoso a los fuegos". En total, de acuerdo con los cálculos del virrey, el monto de las obras -incluyendo la construcción de los nuevos reductos- ascendería a 4000 pesos. $^{74}$

En cuanto a los telégrafos ópticos, hay que señalar que poco después del arribo de Apodaca llegó al virreinato un cargamento con la maquinaria para el establecimiento de la línea, misma que finalmente no se instaló, quizá porque los reductos existentes no tenían las condiciones idóneas para servir como torres telegráficas, por lo que en su lugar se concibió un código para comunicar los distintos puestos del camino a cañonazos, ${ }^{75}$ de esta forma, la tentativa quedó en el olvido, hasta que fue retomada por Bonifacio de Tosta, bajo cuya dirección se construyeron entre 1818 y 1820, varias torres o "telefres" para el funcionamiento del sistema. ${ }^{76}$

Durante los siguientes años, la creciente debilidad de los insurgentes en la región les impidió intentar operaciones de envergadura, por lo que sólo ocasionalmente pudieron disputarle a los realistas el control de la ruta, ${ }^{77}$ lo que motivó que muchas de las obras proyectadas por el gobierno virreinal para robustecer la estructura de defensa de la provincia de Veracruz quedaran inconclusas o fueran canceladas, ${ }^{78}$ salvo por algunas reparaciones menores en las ya construidas, ${ }^{79} \mathrm{o}$ bien por los reductos edificados

${ }^{74}$ Ortiz (2008, pp. 260-261).

75 Archer (1997, p. 167).

${ }^{76}$ Vargas (2018, s/p).

77 De acuerdo con Archer, todavía en 1819 los rebeldes fueron capaces de bloquear nuevamente la ruta de Xalapa, cortando las comunicaciones y el comercio durante varios meses. Archer (2002b, p. 436).

${ }^{78}$ En este conjunto podemos incluir el proyecto de Bonifacio de Tosta para la instalación de la línea telegráfica Xalapa-Veracruz, y los presentados por Manuel Rincón y Manuel León para la construcción del fortín de San Carlos, inmueble que el gobierno virreinal consideró erigir en las inmediaciones del pueblo del mismo nombre, cercano a la barra de Chachalacas en la costa norte de Veracruz. 23 de agosto de 1819, AGN, Operaciones de Guerra, vol. 792, exp. 66, ff. 343-349.

${ }^{79}$ De José Dávila al virrey Apodaca, 6 de junio de 1820, AGN, Operaciones de Guerra, vol. 963, exp. 31, f. 215. 

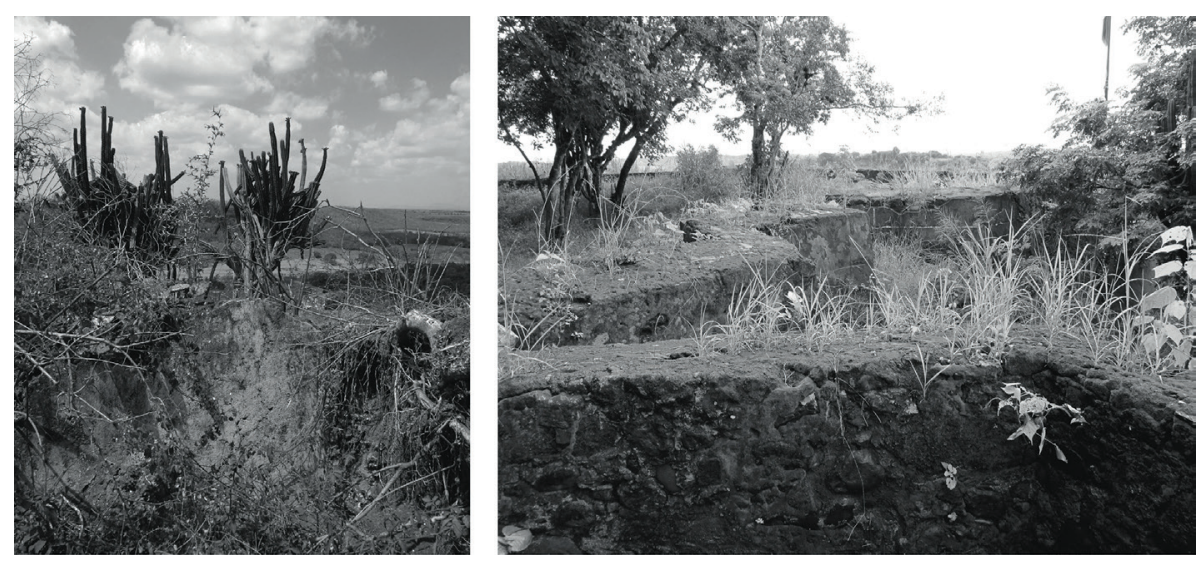

Figura 9. Vestigios del fortín de Fernando VII y la atalaya de La Concepción. Fotografía de Sergio Vargas

en la vía por Orizaba con el propósito de avecindar en sus alrededores a los rebeldes que se habían acogido al indulto. ${ }^{80}$

No obstante, tal como lo afirmó Archer, esta aparente calma ${ }^{81}$ no significó el fin de la insurgencia, ya que con la restauración de la Constitución de Cádiz en $1820,{ }^{82}$ y la subsecuente extinción de las compañías urbanas y

${ }^{80}$ La concentración de los excombatientes y sus familias en ranchos y villorrios bajo la supervisión de los comandantes realistas fue una de las tácticas empleadas por el gobierno virreinal para lograr la pacificación de las zonas bajo la influencia de los insurgentes, tal como ocurrió en el Bajío, el valle de Apan y la provincia de Veracruz, donde se crearon numerosos asentamientos poblacionales con base en este sistema, algunos de los cuales, subsisten en la actualidad. Véanse: Ortiz (2014, pp. 225-226), y Fowler (2011, pp. 71-73).

${ }^{81}$ Esta cuestión ha sido abordada en los últimos años por diversos autores que con diferentes matices rebaten la tesis de Alamán según la cual, desde principios de 1816, "el dominio español no corría ya riesgo alguno", salvo "por las partidas que quedaban esparcidas en una gran parte del reino". Alamán (1849, p. 396). Al respecto, Moreno dice que "las áreas sin control efectivo por parte del gobierno eran mucho más extensas de lo que el conde del Venadito informaba y las gavillas, independentistas o no, dispersas y multifacéticas [...] asolaban con intermitencia numerosas provincias propiciando un escenario que hoy no dudaríamos en calificar como de inseguridad generalizada”. Moreno (2016, pp. 140-141).

${ }^{82} \mathrm{El}$ restablecimiento de la Constitución de 1812 provocó gran inconformidad entre aquellos sectores que se oponían al talante liberal del documento, "sobre todo entre clérigos y militares [...] que, resentidos o temerosos por las novedades, mostraban franca hostilidad hacia el Gobierno”. Así, el rechazo a la aplicación en la Nueva España de las disposiciones emanadas de las Cortes españolas fue la base que sustentó la formación de un nuevo movimiento independentista cuyos integrantes "acertaron a presentarse [...] como el partido del orden y de los genuinos valores amenazados por las reformas liberales", aunque, desmarcándose de "los promotores del primer impulso independentista". Ferrer (1995, pp. 80-81). 
rurales, los jefes realistas se quedaron sin los contingentes necesarios para asestar el golpe definitivo a la revolución, ${ }^{83}$ lo que permitió que líderes rebeldes como Victoria y Vicente Guerrero continuaran la lucha hasta que en febrero de 1821, con la proclamación del Plan de Iguala, el comandante vallisoletano Agustín de Iturbide, de la mano de sus antiguos adversarios, dio por terminado el dominio español en México, lo que apenas unos meses después fue ratificado por el último jefe político superior de la Nueva España, Juan O’Donojú y O’Ryan.

\section{ANEXO \\ CARACTERÍSTICAS Y VENTAJAS \\ DE LAS FORTIFICACIONES TIPO MONTALEMBERT, SEGÚN FERNANDO MiYARES Y MANCEBO}

1a. Las guarniciones de estos fuertes pueden aumentarse o disminuirse considerablemente, sin perjuicio de su buena defensa.

2a. Quedan encerrados en ellos los víveres, municiones y demás efectivos, sin que puedan jamás deteriorarse, ni por las lluvias, ni por los ardores del sol, y por la razón expresada se precave a sus guarniciones de las enfermedades que son consiguientes en este país a todo individuo que sufre la intemperie.

3a. En los expresados fuertes no hay que hacer sino el primer gasto y puede asegurarse que su duración, sin hacer en ellos composición ninguna, podrá ser la de cincuenta años.

4a. Para apoderarse de cada uno de ellos, si son medianamente provistos $\mathrm{y}$ defendidos, se necesita de un sitio formal, pues los ataques bruscos, y aun las sorpresas, están muy distantes de tener lugar en esta especie de obras, si en ellas hay la décima parte de la vigilancia que se requiere en cualquiera otra fortificación.

5a. Su elevación proporciona ventajosamente el establecimiento de telégrafos, circunstancia que no he olvidado y que detallaré si puede ser hoy mismo a fin de que sirva en lo sucesivo, si se juzgase o creyesen necesarios.

${ }^{83}$ Archer (2002b, p. 435). 
El único defecto que se pone a las torres de Montalembert es que sólo tienen en sí una defensa directa y que los defensores no registran el pie del muro de la obra que defienden, pero este defecto ha desaparecido en Órdenes Militares, habiendo yo hecho construir escapes o ladroneras en todos sus frentes, desde las cuales, ya con el fusil, ya con granadas de mano, queda todo perfectamente visto y defendido; esto es, desde el pie del muro hasta la distancia de tiro de cañón no hay un paraje en donde el enemigo pueda establecerse a pecho descubierto, sin que sufra daño, cuando los defensores están tan a cubierto que es muy casual pueda haber en ellos la menor desgracia.

El fuerte de Órdenes Militares puede contener 80 defensores. En su almacén de víveres pueden encerrarse 30000 raciones, y en su almacén de municiones he tenido yo depositados 230000 cartuchos de fusil, 500 tiros de cañón y 600 granadas, quedando aún un gran espacio para que los arrieros transeúntes puedan depositar en ellos lo que gusten y entreguen con cuenta y razón, presentando este recurso a la arriería y al comercio las ventajas que se deducen fácilmente. Aunque he dicho que la guarnición de este fuerte debe ser de 80 hombres, como también he significado que una de las primeras ventajas que en sí encierra es que esta guarnición pueda sufrir alteraciones en su fuerza, sin perjuicio de su buena defensa, he determinado que en el día sólo haya un oficial con 20 hombres, y siendo estos los únicos que lo guarnecen, estoy bien seguro de que el punto está perfectamente bien guardado.

Habiendo estado ocupado al tiempo de la construcción de los fuertes con otra porción de asuntos, no pude contraerme a aquélla, y ésta es la razón que me impide a dar a vuestra excelencia una noticia exacta del costo de los expresados fuertes, pero me parece que no me separaré mucho de la verdad en el concepto que formo de él haciéndolo ascender a 2600 pesos cada uno, debiendo poner en la superior consideración de vuestra excelencia que en La Antigua, Santa Fe y San Juan no hay necesidad de hacerlos tan espaciosos como el de Órdenes Militares, y que en consecuencia costarán menos, supuesta una igualdad de circunstancias. 


\section{BIBLIOGRAFÍA}

Alamán, L. (1849). Historia de México desde los primeros movimientos que prepararon su Independencia en el año de 1808 hasta la época presente. Tomo cuarto. México: Imprenta de J. M. Lara.

Archer, C. (2005). La militarización de la política mexicana. En Kuethe, A. J., y Marchena, J. (eds.), Soldados del Rey. El ejército borbónico en vísperas de la Independencia (pp. 253-277). Castelló de la Plana: Publicacions de la Universitat Jaume I.

(2008). Las tropas expedicionarias españolas en la guerra de Independencia de México, 1810-1822. En J. Ortiz Escamilla (coord.), Revisión histórica de la guerra de Independencia en Veracruz (pp. 197-228). México: Comisión para la Conmemoración del Bicentenario de la Independencia Nacional y del Centenario de la Revolución Mexicana/Universidad Veracruzana/sEv-Gobierno del Estado de Veracruz.

(2002a). Ciudades en la tormenta: el impacto de la contrainsurgencia realista en los centros urbanos, 1810-1821. En Broseta, S.; Corona, C.; Chust, M.; Feliu, J.; Mínguez, V.; Ortells, V.; Piqueras, J.; Poveda, A.; Rambla, W.; Rodríguez, I., y Sanz, V. (eds.), Las ciudades y la guerra, 1750-1898 (pp. 335-360). Castelló de la Plana: Publicacions de la Universitat Jaume I.

(2002b). En busca de una victoria definitiva: el ejército realista en Nueva España, 1810-1821. Serrano Ortega, J. A., y Terán, M. (eds.), Las guerras de Independencia en la América española (pp. 423-437). Zamora: El Colegio de Michoacán/Instituto Nacional de Antropología e Historia/Universidad Michoacana de San Nicolás de Hidalgo.

(1997). La revolución militar de México: estrategia, tácticas y logísticas durante la guerra de Independencia. 1810-1821. En Vázquez, J. Z. (coord.), Interpretaciones de la Independencia de México (pp. 123-176). México: Editorial Patria.

Arrioja Díaz Viruell, L. A., y Sánchez Silva, C. (2011). Melchor Álvarez Thomas, comandante general de la intendencia de Oaxaca, 1813-1818. En Olveda, J. (coord.), Los comandantes realistas y la guerra de Independencia (pp. 219-252). Zapopan: El Colegio de Jalisco.

Berbesí de SAlazar, L. (2014). Genealogía social de los gobernadores de la Provincia de Maracaibo 1787-1812. Procesos Históricos, 3-6, 33-57.

BERNÁlDEZ, E. (1860). La fortificación moderna o consideraciones generales sobre el estado actual del arte de fortificar las plazas. Madrid: Imprenta del Memorial de Ingenieros. 
CoRsini, L. (1849). Vocabulario militar que comprende las definiciones elementales del arte de la guerra y la tecnología especial de las diversas armas que le constituyen, de la táctica peculiar a cada una, de la sublime, de la estrategia, de la logística y de la fortificación, castramentación y equitación. Madrid: Imprenta del Semanario.

Ferrer Muñoz, M. (1995). La formación de Estado nacional en México. México: Universidad Nacional Autónoma de México.

Florescano Mayet, S. (1987). El camino México-Veracruz en la época colonial. México: Universidad Veracruzana.

Fowler, W. (2010). Santa Anna. Xalapa: Universidad Veracruzana.

Grafenstein, J. (2001). Insurgencia y contrainsurgencia en el golfo de México, 1812-1820. En Guedea, V. (coord.), La Independencia de México y el proceso autonomista novohispano 1808-1824 (pp. 185-227). México: Universidad Nacional Autónoma de México/Instituto de Investigaciones Dr. José María Luis Mora.

GuZmán PÉrez, M. (2006). Las economías de guerra en la independencia de México, 1810-1821. En Guzmán Pérez, M. (coord.), Entre la tradición y la modernidad. Estudios sobre la Independencia (pp. 315-351). Morelia: Universidad Michoacana de San Nicolás de Hidalgo.

Hernández y DÁvalos, J. (2008). En Guedea, V., y Ávila, A. (coords.), Colección de documentos para la historia de la guerra de Independencia en México de 1808 a 1821. T. IV. México: Universidad Nacional Autónoma de México.

Humboldt, A. (1822). Ensayo político sobre el reino de la Nueva España. T. cuarto. París: Casa de Rosa.

JunQuera y SÁnchez, I. (1866). Elementos de fortificación moderna. Madrid: Imprenta y Estereotipia de M. Rivadeneyra.

Marchena, J. (2008). ¿Obedientes al rey y desleales a sus ideas? Los liberales españoles ante la "reconquista" de América durante el primer absolutismo de Fernando VII, 1814-1820. En Marchena, J., y Chust, M. (eds.), Por la fuerza de las armas. Ejército e independencias en Iberoamérica (pp. 143-220). Castelló de la Plana: Universitat Jaume I.

MARICHAL, C., y Souto, M. (2012). La Nueva España y el financiamiento del Imperio español en América: los situados para el Caribe en el siglo XVIII. En Marichal, C., y Grafenstein, J. (coords.), El secreto del Imperio español. Los situados coloniales en el siglo XVIII (pp. 61-93). México: El Colegio de México/Instituto de Investigaciones Dr. José María Luis Mora.

MARTIRÉ, E. (2012). "Fernando VII y las Indias (1814-1833). Primera parte (18141820). Revista Historia del Derecho, 44, 108-127.

Moreno GutiérRez, R. (2016). La trigarancia. Fuerzas armadas en la consumación de la Independencia. Nueva España, 1820-1821. México: Universidad Nacional Autónoma de México. 
Ortiz Escamilla, J. (2017). Calleja: guerra, botín y fortuna. Xalapa/Zamora: Universidad Veracruzana/El Colegio de Michoacán. (2014). Guerra y gobierno. Los pueblos y la independencia de México, 18081825. México: El Colegio de México/Instituto de Investigaciones Dr. José María Luis Mora.

(2008). Veracruz en armas. Vol. I. México: Gobierno del Estado de Veracruz/Universidad Veracruzana.

Pérez GonzÁlez, M. (2001). Los caminos reales de América en la legislación y la historia. Anuario de Estudios Americanos, 58-1, 33-60.

ReEs, P. (1976). Transporte entre México y Veracruz, 1519-1910. México: Secretaría de Educación Pública.

Rivera Cambas, M. (1869). Historia antigua y moderna de Xalapa y de las revoluciones del estado de Veracruz. T. III. México: Imprenta de I. Cumplido.

Rodríguez Venegas, C. (2002). Las políticas ministeriales durante la regencia y el Imperio. En Ludlow, L. (coord.), Los secretarios de Hacienda y sus proyectos (pp. 29-54). Tomo uno. México: Universidad Nacional Autónoma de México.

Roig, S. O. (2007). Distintas etapas de la telegrafía óptica en España. Cuadernos de Historia Contemporánea, 29, 29-34.

SAUCEDo ZarCo, C. (2014). La convención de las provincias orientales. Un proyecto de gobierno insurgente. En Serrano Ortega, J. A. (coord.), El sexenio absolutista, los últimos años insurgentes. Nueva España (1814-1820) (pp. 375396). Zamora: El Colegio de Michoacán.

Sociedad de Literatos (1832). Diccionario geográfico universal. Vol. vir. Barcelona: Imprenta de José Torner.

Stein, S. J., y Stein, B. H. (2005). El apogeo del imperio. España y Nueva España en la era de Carlos III, 1759-1789. Barcelona: Crítica.

Valle Pavón, G. (2007a). Articulación de mercados y la reconstrucción del camino México-Veracruz vía Orizaba a fines del siglo Xviı. En Oikón Solano, V. (ed.), Historia, nación y región (pp. 437-460). Vol. II. Zamora: El Colegio de Michoacán.

(2007b). Desarrollo de la economía mercantil y construcción de los caminos México-Veracruz en el siglo xvi. América Latina en la Historia Económica, 27, 7-49.

(2000). Oposición de los mercaderes de México a las reformas comerciales mediante la resistencia a otorgar crédito a la Corona. En Yuste, C., y Souto, M. (coords.), El comercio exterior de México 1713-1850. Entre la quiebra del sistema imperial y el surgimiento de una nación (pp. 84-109). México: Instituto de Investigaciones Dr. José María Luis Mora/Universidad Nacional Autónoma de México/Universidad Veracruzana. 


\section{SOBRE EL AUTOR}

Sergio A. Vargas Matías es doctor en Estudios Socioculturales por la Universidad Autónoma de Aguascalientes. Actualmente realiza una estancia posdoctoral en el Instituto de Investigaciones Históricas de la Universidad Michoacana de San Nicolás de Hidalgo. Su trabajo está enfocado a la historia militar y la historia regional de la provincia de Veracruz y el Camino Real durante la guerra de Independencia. Entre sus publicaciones más recientes destaca "Entre la niebla del valle y las brumas de la locura. El camino militar México-Puebla y su constructor, el ingeniero Valentín de Ampudia Grimarest”. 
